\title{
GNREL
}

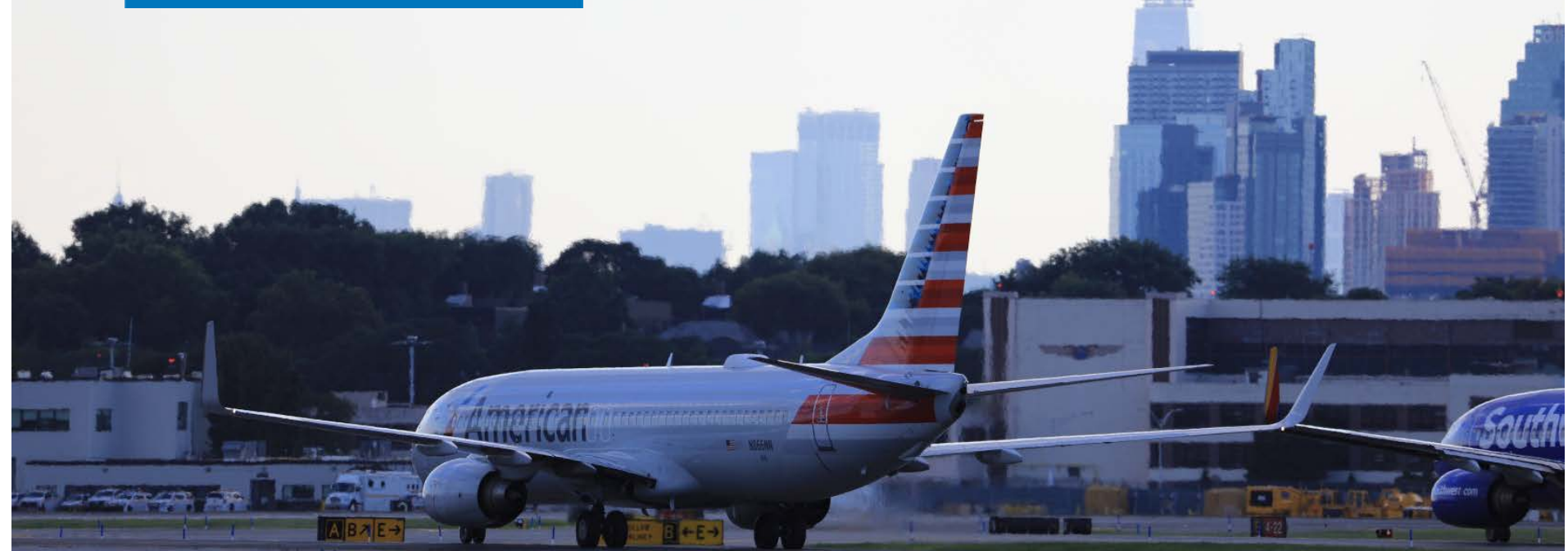

\section{Port Authority of New York and New Jersey Sustainable Aviation Fuel Logistics and Production Study}

Kristi Moriarty, Anelia Milbrandt, and Ling Tao

National Renewable Energy Laboratory

NREL is a national laboratory of the U.S. Department of Energy Office of Energy Efficiency \& Renewable Energy

Operated by the Alliance for Sustainable Energy, LLC

This report is available at no cost from the National Renewable Energy Laboratory (NREL) at www.nrel.gov/publications.
Technical Report

NREL/TP-5400-80716

October 2021 


\section{GNREL}

\section{Port Authority of New York and New}

Jersey Sustainable Aviation Fuel Logistics and Production Study

Kristi Moriarty, Anelia Milbrandt, and Ling Tao

National Renewable Energy Laboratory

\section{Suggested Citation}

Moriarty, Kristi, Anelia Milbrandt, and Ling Tao. 2021. Port Authority of New York and New Jersey Sustainable Aviation Fuel Logistics and Production Study. Golden, CO: National Renewable Energy Laboratory. NREL/TP-5400-80716.

https://www.nrel.gov/docs/fy22osti/80716.pdf.

NREL is a national laboratory of the U.S. Department of Energy Office of Energy Efficiency \& Renewable Energy Operated by the Alliance for Sustainable Energy, LLC

This report is available at no cost from the National Renewable Energy Laboratory (NREL) at www.nrel.gov/publications.

Contract No. DE-AC36-08GO28308
Technical Report

NREL/TP-5400-80716

October 2021

National Renewable Energy Laboratory 15013 Denver West Parkway Golden, CO 80401

303-275-3000 • www.nrel.gov 


\section{NOTICE}

This work was authored by the National Renewable Energy Laboratory, operated by Alliance for Sustainable Energy, LLC, for the U.S. Department of Energy (DOE) under Contract No. DE-AC36-08GO28308. Funding provided by the Port Authority of New York and New Jersey. The views expressed herein do not necessarily represent the views of the DOE or the U.S. Government.

This report is available at no cost from the National Renewable

Energy Laboratory (NREL) at www.nrel.gov/publications.

U.S. Department of Energy (DOE) reports produced after 1991

and a growing number of pre-1991 documents are available

free via www.OSTI.gov.

Cover Photo provided courtesy of The Port Authority of New York and New Jersey for use in this report.

NREL prints on paper that contains recycled content. 


\section{Foreword}

The Port Authority of New York and New Jersey hired the National Renewable Energy

Laboratory to review the potential to produce sustainable aviation fuel in the region and identify locations to blend the fuel for delivery to four port-owned airports. 


\section{Acknowledgments}

The authors appreciate the input from fuel supply companies, airlines, airports, and the staff from the Port Authority of New York and New Jersey. 


\section{List of Acronyms}

$\mathrm{CO}_{2}$

DCO

EWR

FOG

FT

gge

$\mathrm{HC}$

HEFA

HFS

JFK

LGA

MFSP

MMgge

MSW

NREL

PANYNJ

RIN

SAF

SIP

SKA

SPK

TEA

TEB

UCO carbon dioxide

distillers corn oil

Newark Liberty International Airport

fats, oils, greases

Fischer-Tropsch

gallon of gasoline equivalent

hydrocarbon

hydroprocessed esters and fatty acids

hydroprocessed fermented sugars

John F. Kennedy International Airport

LaGuardia Airport

minimum fuel selling price

million gallons of gasoline equivalent

municipal solid waste

National Renewable Energy Laboratory

Port Authority of New York and New Jersey

Renewable Identification Number

sustainable aviation fuel

synthetic isoparaffins

synthetic kerosene with aromatics

synthetic paraffinic kerosene

techno-economic analysis

Teterboro Airport

used cooking oil 


\section{Executive Summary}

The Port Authority of New York and New Jersey (PANYNJ) sustainability commitment is to meet the goals set by the Paris Agreement, with an interim greenhouse gas reduction target of $35 \%$ by 2025 and $80 \%$ by 2050 . PANYNJ is seeking sustainable solutions to reduce carbon emissions for all public forms of transportation, including aviation. Similarly, the global aviation industry adopted the Carbon Offsetting and Reduction Scheme for International Aviation (CORSIA), which seeks to cap net carbon dioxide $\left(\mathrm{CO}_{2}\right)$ aviation emissions at 2020 levels through 2035. The International Air Transport Association has also set a goal of reducing $\mathrm{CO}_{2}$ emissions by $50 \%$ compared to 2005 levels by 2050 .

Sustainable aviation fuel (SAF), made from non-petroleum feedstocks, is a near-term alternative fuel that reduces emissions from air transportation. Compared with conventional jet fuel, neat SAF has the potential to reduce greenhouse gas emissions by an estimated range of $26 \%$ to $94 \%$ depending on feedstock and technology pathway (Monfort 2019; Prussi 2021). ${ }^{1}$ Aircraft movements account for $37 \%$ of $\mathrm{PANYNJ} \mathrm{CO}_{2}$ emissions, and $\mathrm{SAF}$ represents an opportunity to reduce aircraft emissions (SC\&A 2020). PANYNJ has long been involved in finding ways to bring SAF to its airports. This report evaluates the potential for SAF production in the region and identifies logistics for blending SAF with Jet A for delivery to PANYNJ airports. Logistics were reviewed for John F. Kennedy International Airport (JFK), LaGuardia Airport (LGA), Newark Liberty International Airport (EWR), and Teterboro Airport (TEB).

Although SAF could be sourced from other areas of the United States or imported, an evaluation of local production was conducted due to the potential positive impacts of a circular economy by converting local waste feedstocks into SAF for use at nearby airports. There are two commercial plants - one foreign and the other located in California. Several other plants are under

construction, though none are in the Northeast. A resource assessment for a potential biorefinery was conducted to determine SAF feedstock availability in close proximity (for resources that are typically not transportable, such as biogas) and within a 50-, 100-, and 200-mile radius of the port district. ${ }^{2}$ Closer proximity to feedstocks reduces production costs. As shown in Table ES-1, Table ES-2, and

Table ES-3, the highest volumes of feedstock are select organic municipal solid waste (MSW) and woody biomass.

A techno-economic analysis (TEA) was conducted using data from the resource assessment. It should be emphasized that the TEA outputs carry some uncertainty related to the assumptions made for capital and raw material costs. Any new plant could have different capital and input costs that would impact the overall costs and economics that determine if a plant is viable. The TEA outputs are best used to compare different pathways and feedstocks against one another. Technology pathways selected were based on feedstock type: Fischer-Tropsch (FT) synthetic paraffinic kerosene (SPK) was used for select organic MSW and woody biomass; hydroprocessed esters and fatty acids (HEFA)-SPK was used for animal fats, used cooking oil

\footnotetext{
${ }^{1}$ The estimated range is based on a baseline for conventional jet fuel of 89 grams of $\mathrm{CO}_{2}$ equivalent per megajoule $\left(\mathrm{CO}_{2} \mathrm{e} / \mathrm{MJ}\right)$ and the best potential reduction from SAF of $5.2 \mathrm{CO}_{2} \mathrm{e} / \mathrm{MJ}$ for MSW with the FT pathway, versus 65.7 $\mathrm{CO}_{2} \mathrm{e} / \mathrm{MJ}$ for corn converted by the ethanol to jet pathway. The emissions reduction benefit depends on the percent of SAF blended with Jet A.

${ }^{2}$ The port district is an area of jurisdiction within 25 miles of the Statue of Liberty.
} 
(UCO), trap grease, and soybean oil; and hydroprocessed fermented sugars to synthetic isoparaffins was used for crop residues. Data were generated using Aspen Plus process simulation using a set of conversion parameters, material and energy balance, and flow rate. ${ }^{3}$ These data are used to size and cost process equipment and compute raw material and other operating costs. Based on a discounted cash flow rate of return, the analysis determined the minimum fuel selling price (MFSP) required to obtain a net present value of zero for a $10 \%$ internal rate of return. ${ }^{4}$

Tables ES-1, ES-2, and ES-3 summarize results for 50-, 100-, and 200-mile radius, respectively. The tables show feedstock availability, potential SAF production, total hydrocarbon (HC) production in million gallons of gasoline equivalent (MMgge) and thousand tonnes, and the MFSP (in 2017 U.S. dollars). In the same way petroleum refineries produce multiple fuels, SAF production plants also make other renewable $\mathrm{HC}$ fuels, and total plant production is provided in the tables. The lowest MFSPs were for MSW and woody biomass due their abundant availability nearby. ${ }^{5}$ Higher MFSP costs reflect low feedstock availability and an inability of a plant to benefit from economies of scale.

Total capital investment (TCI) per annual gge of fuel is also listed in the Table ES-1, ES-2, and ES-3. This parameter illustrates challenges on capital investment. For example, although MSFP for both MSW and woody biomass to SAF pathways are low, the TCI/annual gge of fuel produced are high. This indicates significant capital investment would be required for constructing the biorefinery facilities. This partially explains why there is limited investment being made today on these technologies even though they are cost competitive with economy of scales. Technology challenges and risks for large scale commercialization for individual pathways have not been explored extensively in this report.

Table ES-1. 50-Mile Radius SAF Feedstocks, Production Potential, and Minimum Selling Price

\begin{tabular}{|c|c|c|c|c|c|c|c|}
\hline Feedstock & $\begin{array}{l}\text { Availability } \\
\text { (tonnes/yr) }\end{array}$ & $\begin{array}{l}\text { SAF } \\
\text { Production } \\
\text { via Annex-1 } \\
\text { (MMgge/yr) }\end{array}$ & $\begin{array}{l}\text { SAF } \\
\text { Production } \\
(1,000 \\
\text { tonnes })\end{array}$ & $\begin{array}{l}\text { Total HC } \\
\text { Production } \\
\text { (MMgge/yr) }\end{array}$ & $\begin{array}{l}\text { Total HC } \\
\text { Production } \\
(1,000 \\
\text { tonnes) }\end{array}$ & $\begin{array}{l}\text { \$TCI per } \\
\text { Annual } \\
\text { gge }\end{array}$ & $\begin{array}{l}\text { MFSP } \\
\text { (\$/gallon) }\end{array}$ \\
\hline Animal fats & 1,650 & 0.3 & 0.7 & 0.3 & 1 & $\$ 58.2$ & $\$ 38.39$ \\
\hline Crop residues & 75,000 & 3 & 10 & - & - & $\$ 50.0$ & $\$ 9.72$ \\
\hline $\begin{array}{l}\text { MSW (paper, } \\
\text { yard waste, and } \\
\text { clean wood) }\end{array}$ & $4,000,000$ & 101 & 312 & 326 & 716 & $\$ 9.4$ & $\$ 2.53$ \\
\hline $\begin{array}{l}\text { UCO and trap } \\
\text { grease }\end{array}$ & 175,000 & 33 & 91 & 43 & 123 & $\$ 4.9$ & $\$ 3.44$ \\
\hline Woody biomass & $2,542,000$ & 71 & 198 & 159 & 455 & $\$ 9.4$ & $\$ 2.44$ \\
\hline
\end{tabular}

\footnotetext{
${ }^{3}$ https://www.aspentech.com/en

${ }^{4}$ Methodology and assumptions are available in Section 2.2.1 of this report.

${ }^{5}$ The model assumes feedstock arrive ready for use at the plant gate. For example, the model assumes MSW is sorted prior to delivery to the plant.
} 
Table ES-2. 100-Mile Radius SAF Feedstocks, Production Potential, and Minimum Selling Price

\begin{tabular}{llllllll}
\hline Feedstock & $\begin{array}{l}\text { Availability } \\
\text { (tonnes/yr) }\end{array}$ & $\begin{array}{l}\text { SAF } \\
\text { Production } \\
\text { via Annex-1 } \\
\text { (MMgge/yr) }\end{array}$ & $\begin{array}{l}\text { SAF } \\
\text { Production } \\
(\mathbf{1 , 0 0 0} \\
\text { tonnes) }\end{array}$ & $\begin{array}{l}\text { Total HC } \\
\text { Production } \\
\text { (MMgge/yr) }\end{array}$ & $\begin{array}{l}\text { Total HC } \\
\text { Production } \\
\text { (1,000 } \\
\text { tonnes) }\end{array}$ & $\begin{array}{l}\text { \$TCI per } \\
\text { Annual } \\
\text { gge }\end{array}$ & $\begin{array}{l}\text { MFSP } \\
\text { (\$/gallon) }\end{array}$ \\
\hline Animal fats & 5,500 & 1 & 2 & 1 & 4 & $\$ 31.2$ & $\$ 15.54$ \\
\hline $\begin{array}{l}\text { Crop residues } \\
\text { MSW (paper, }\end{array}$ & 426,000 & 19.82 & 55 & - & - & $\$ 21.8$ & $\$ 6.04$ \\
$\begin{array}{l}\text { yard waste, and } \\
\text { clean wood) }\end{array}$ & $7,400,000$ & 187 & 418 & 532 & 1,325 & $\$ 8.3$ & $\$ 2.35$ \\
$\begin{array}{l}\text { UCO and trap } \\
\text { grease }\end{array}$ & 290,000 & 55 & 151 & 72 & 203 & $\$ 4.0$ & $\$ 3.23$ \\
\hline \begin{tabular}{l} 
Woody biomass \\
\hline
\end{tabular} & $4,504,000$ & 126 & 351 & 283 & 807 & $\$ 8.2$ & $\$ 2.24$ \\
\hline
\end{tabular}

Table ES-3. 200-Mile Radius SAF Feedstocks, Production Potential, and Minimum Selling Price

\begin{tabular}{|c|c|c|c|c|c|c|c|}
\hline Feedstock & $\begin{array}{l}\text { Availability } \\
\text { (tonnes/yr) }\end{array}$ & $\begin{array}{l}\text { SAF } \\
\text { Production } \\
\text { via Annex-1 } \\
\text { (MMgge/yr) }\end{array}$ & $\begin{array}{l}\text { SAF } \\
\text { Production } \\
(1,000 \\
\text { tonnes) }\end{array}$ & $\begin{array}{l}\text { Total HC } \\
\text { Production } \\
\text { (MMgge/yr) }\end{array}$ & $\begin{array}{l}\text { Total HC } \\
\text { Production } \\
(1,000 \\
\text { tonnes })\end{array}$ & $\begin{array}{l}\$ T C I \\
\text { per } \\
\text { Annual } \\
\text { gge }\end{array}$ & $\begin{array}{l}\text { MFSP } \\
\text { (\$/gallon) }\end{array}$ \\
\hline Animal fats & 106,000 & 17 & 55 & 20 & 73 & $\$ 7.9$ & $\$ 4.45$ \\
\hline Crop residues & $2,900,000$ & 135 & 376 & - & - & $\$ 12.1$ & $\$ 5.39$ \\
\hline $\begin{array}{l}\text { MSW (paper, } \\
\text { yard waste, and } \\
\text { clean wood) }\end{array}$ & $12,300,000$ & 310 & 959 & 694 & 2,203 & $\$ 7.6$ & $\$ 2.24$ \\
\hline Soybean oil & 158,000 & 26 & 73 & 41 & 115 & $\$ 5.2$ & $\$ 3.74$ \\
\hline $\begin{array}{l}\text { UCO and trap } \\
\text { grease }\end{array}$ & 488,000 & 92 & 254 & 121 & 342 & $\$ 3.2$ & $\$ 3.07$ \\
\hline Woody biomass & $9,610,000$ & 269 & 749 & 603 & 1,721 & $\$ 7.6$ & $\$ 2.06$ \\
\hline
\end{tabular}

SAF must be blended with Jet A up to certain percent determined by ASTM International fuel quality standards prior to use in aircraft. A previous report identified fuel terminals as the optimal location for blending SAF from a stand-alone facility (Moriarty and Kvien 2021). ${ }^{6}$ The method of moving fuels throughout the country depends on the location of production, fuel type, and volume. The modes of transport for fuels include barge/ship, pipeline, rail, and truck. Emerging biofuels tend to travel initially by rail and truck, then by barge as volumes grow.

Buckeye's Linden fuel terminal supplies jet fuel via pipeline to EWR, JFK, and LGA and does not blend fuels. An assessment of upstream fuel terminals was conducted to identify potential locations for SAF and Jet A blending. Figure ES-1 shows connected terminals and Table ES-4 summarizes the modes by which each terminal can receive fuel. Although all the terminals shown in Table ES-4 are capable of blending SAF and Jet A, Buckeye's Perth Amboy and Shell's Sewaren terminals currently handle jet fuel and are able to receive fuel by all modes of transport, allowing for flexibility in receiving domestic and imported SAF. None of the terminals

\footnotetext{
${ }^{6}$ If SAF is co-processed with conventional Jet A at an existing petroleum refinery, a Refinery Certificate of Quality would be generated at the refinery and the fuel would flow through the supply chain in a business-as-usual model via pipeline or truck to an airport.
} 
are immediately ready to blend SAF, and a capital investment would be needed to add dedicated infrastructure such as lines and pumps to avoid contamination.

Considerations for SAF at PANYNJ airports include:

- The investment in infrastructure will occur upstream at a fuel terminal.

- There are no anticipated changes to airport infrastructure or refueling procedures to accommodate a SAF/Jet A blend. The blended fuel delivered to the airports will be stored and dispensed to aircraft as it is today.

- SAF produced at a nearby production facility would be delivered by truck to one of the terminals shown in Figure ES-1. Domestic SAF produced in another region would be delivered by rail, truck, or barge to the same terminal(s). Imported SAF would arrive by shipe to the same terminal(s).

- There is also the potential to blend domestic or imported SAF in the Gulf region and ship it on the Colonial pipeline, which is connected to the terminals in Figure ES-1.

- EWR, JFK, and LGA receive fuel via pipeline from Buckeye's Linden terminal, which does not blend fuels. Blending SAF and Jet A could occur at one of the connected terminals and be delivered to each airport by pipeline (Figure ES-1).

- $\quad$ TEB receives the majority of their fuel by truck from Shell's Sewaren terminal. It is expected that SAF would be blended with Jet A at Shell's terminal and the blended fuel would be delivered by the same trucks that deliver fuel today.

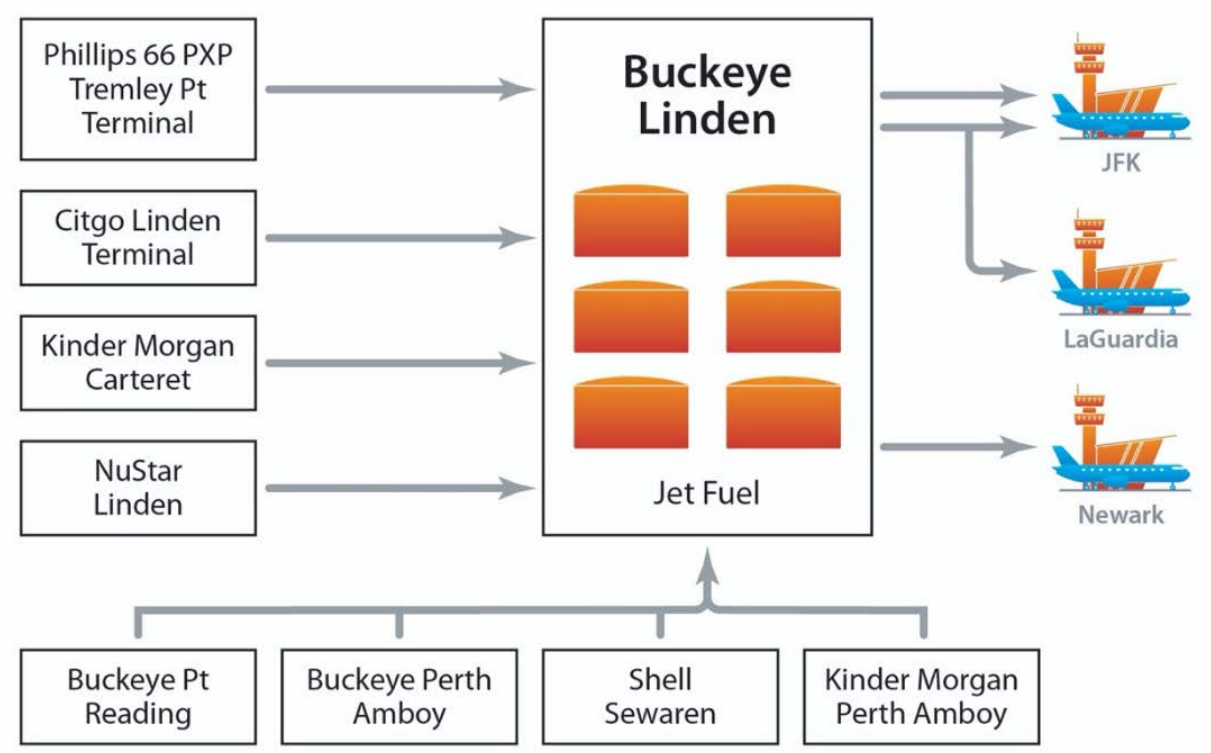

Figure ES-1. Terminals connected to Buckeye Linden ${ }^{7}$

Notes: TEB receives fuel by truck, the majority from Shell's Sewaren terminal.

Source: Buckeye Partners, L.P.

\footnotetext{
${ }^{7}$ Linden terminal delivers fuel to EWR, JFK, and LGA. Buckeye has three pipelines serving the airports - one solely for EWR, one that serves JFK and Long Island McArthur Airport, and a combined pipeline that serves both JFK and LGA (Appendix A). Terminals on the left side of the graphic each have a pipeline connecting to Linden. Terminals on the bottom of the graphic connect to Linden via two shared pipelines.
} 
Table ES-4. Terminal Fuel Receipt Modes

\begin{tabular}{|c|c|c|c|c|c|}
\hline \multirow{2}{*}{ Terminal } & \multicolumn{5}{|c|}{ Modes of Receipt } \\
\hline & Barge & Pipeline & Rail & Ship & Truck \\
\hline Buckeye Linden & $x$ & $\sqrt{ }$ & $x$ & $x$ & $x$ \\
\hline Buckeye Perth Amboy & $\checkmark$ & $\checkmark$ & $\checkmark$ & $\sqrt{ }$ & $\checkmark$ \\
\hline Buckeye Port Reading & $\sqrt{ }$ & $\sqrt{ }$ & $\sqrt{ }$ & $\sqrt{ }$ & $\sqrt{ }$ \\
\hline Citgo Linden & $\sqrt{ }$ & $\sqrt{ }$ & $\sqrt{ }$ & $\sqrt{ }$ & $x$ \\
\hline Kinder Morgan Carteret & $\sqrt{ }$ & $\sqrt{ }$ & $\sqrt{ }$ & $\sqrt{ }$ & $x$ \\
\hline Kinder Morgan Perth Amboy & $\checkmark$ & $\sqrt{ }$ & $x$ & $\sqrt{ }$ & $x$ \\
\hline NuStar Linden & $\sqrt{ }$ & $\sqrt{ }$ & $x$ & $\sqrt{ }$ & $\checkmark$ \\
\hline Phillips 66 Tremley & $\sqrt{ }$ & $\sqrt{ }$ & $x$ & $x$ & $\checkmark$ \\
\hline Shell Sewaren & $\sqrt{ }$ & $\sqrt{ }$ & $\sqrt{ }$ & $\sqrt{ }$ & $\sqrt{ }$ \\
\hline
\end{tabular}




\section{Table of Contents}

1 Introduction ............................................................................................................................... 1

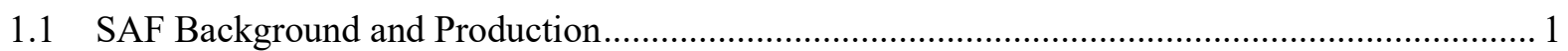

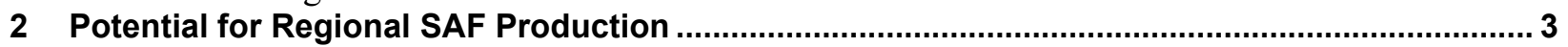

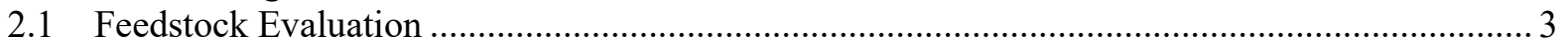

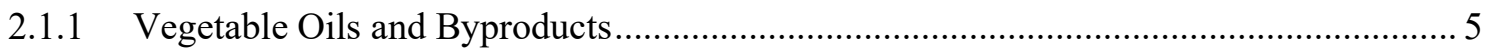

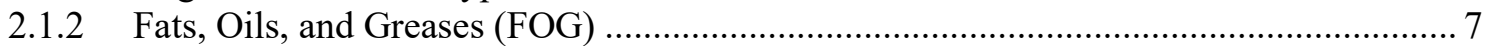

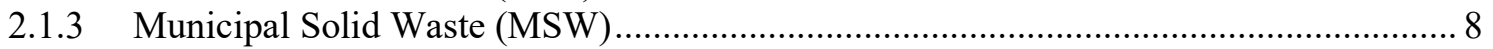

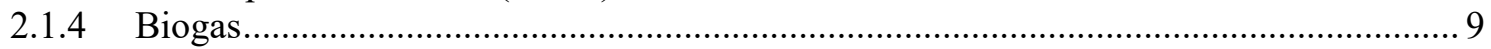

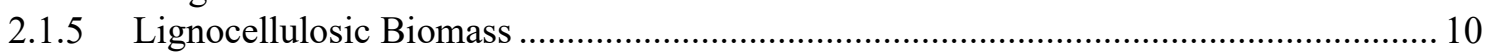

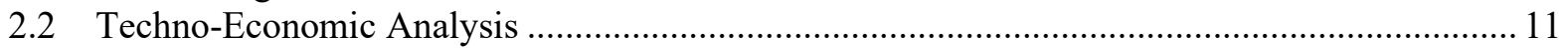

2.2.1 Techno-Economic Analysis Methodology …......................................................... 12

2.2.2 Vegetable Oils; Fats, Oils, and Greases; and Used Cooking Oil SAF Production

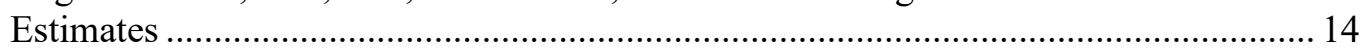

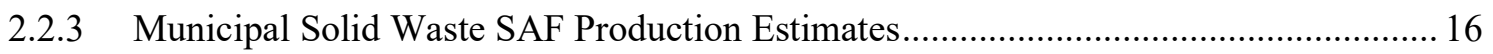

2.2.4 Woody Biomass SAF Production Estimates ............................................................. 17

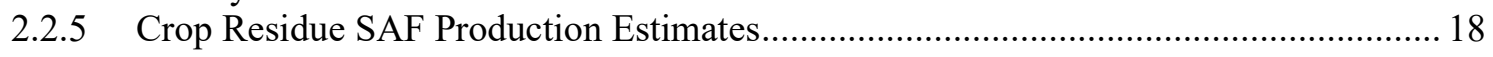

2.3 Role of Airlines and Airport Owners in SAF Production ........................................................ 19

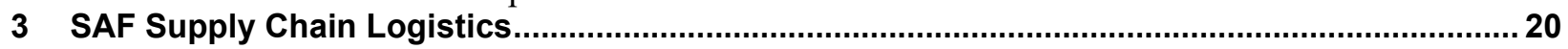

3.1 Port District Terminal Options for Blending SAF and Jet A ….......................................... 23

3.2 PANYNJ Airport Fuel Assets and SAF Delivery to Each Airport ............................................. 30

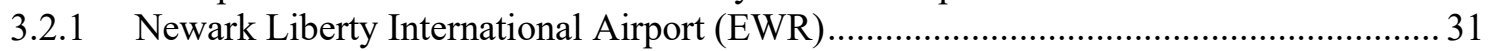

3.2.2 John F. Kennedy International Airport (JFK) ....................................................... 31

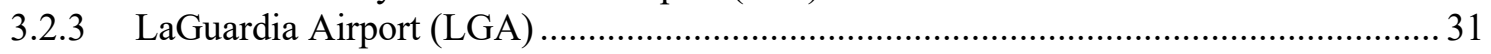

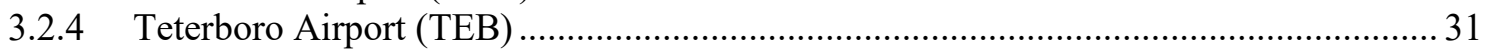

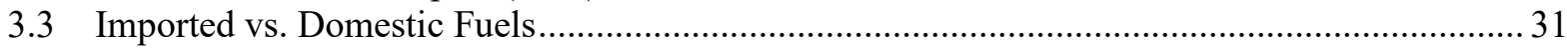

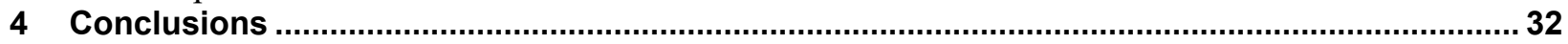

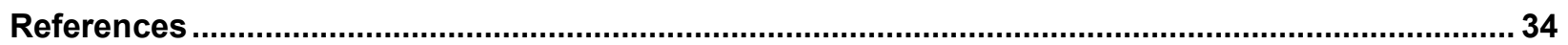

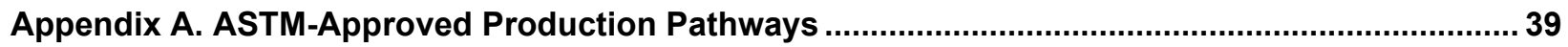

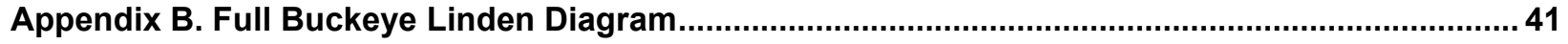




\section{List of Figures}

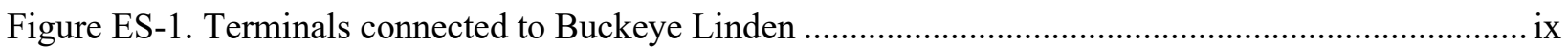

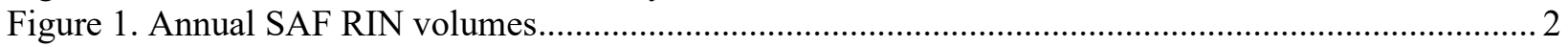

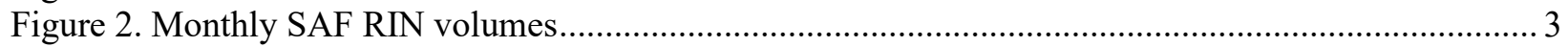

Figure 3. Soybean production by county, oilseed processing facilities, and corn ethanol plants ................ 6

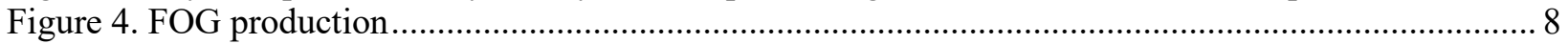

Figure 5. MSW (paper, yard waste, and clean wood) generation by county in 2019 ............................. 9

Figure 6. Methane generation potential from wastewater and food waste near the port district ............... 10

Figure 7. Crop residues and woody biomass potential by county....................................................... 11

Figure 8. Cost impacts from variations of feedstock costs, plant scales, and types of oil feedstocks ........ 16

Figure 9. Cost variations from three scenarios and MSW feedstock prices .......................................... 17

Figure 10. Cost variations from three scenarios and woody feedstock prices ....................................... 18

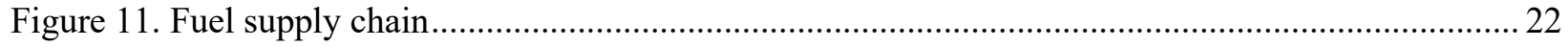

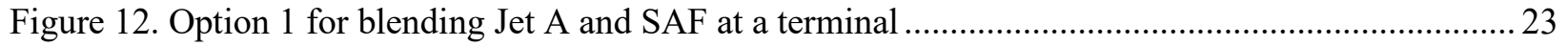

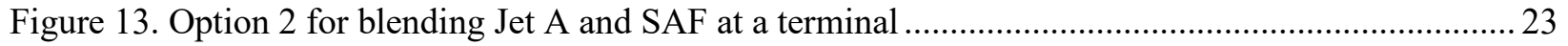

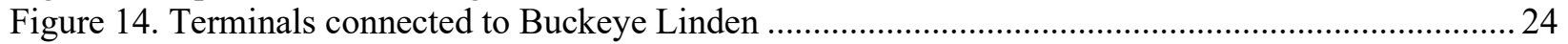

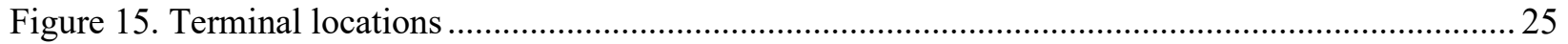

\section{List of Tables}

Table ES-1. 50-Mile Radius SAF Feedstocks, Production Potential, and Minimum Selling Price............vii

Table ES-2. 100-Mile Radius SAF Feedstocks, Production Potential, and Minimum Selling Price......... viii

Table ES-3. 200-Mile Radius SAF Feedstocks, Production Potential, and Minimum Selling Price.........viii

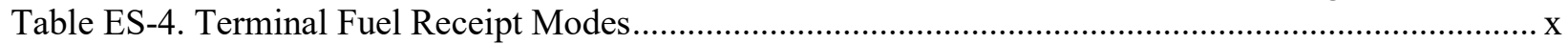

Table 1. US Soybean Oil Production by Region in 2019 ................................................................. 5

Table 2. Estimated FOG Production Within 50-, 100-, and 200-Mile Radius of the Port District.............. 8

Table 3. Estimated Crop Residues and Woody Biomass Potential Within 50-, 100-, and 200-Mile Radius

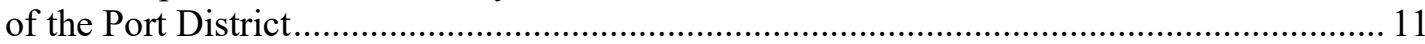

Table 4. Summary of Blending Limitations and Feedstocks for Seven ASTM-Approved Pathways ........ 12

Table 5. HEFA Soybean SAF Production and Minimum Fuel Selling Price ........................................... 14

Table 6. HEFA FOG SAF Production and Minimum Fuel Selling Price ................................................ 15

Table 7. HEFA UCO SAF Production Potential and Minimum Fuel Selling Price .................................. 15

Table 8. Select Organic MSW SAF Production Potential and Minimum Fuel Selling Price ..................... 17

Table 9. Woody Biomass SAF Production Potential and Minimum Fuel Selling Price............................ 18

Table 10. Crop Residue SAF Production and Minimum Fuel Selling Price............................................. 19

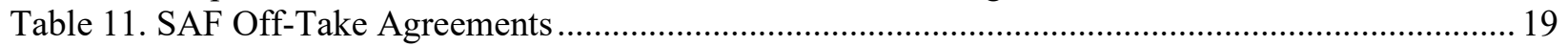

Table 12. Terminal Fuel Receipt Modes....................................................................................... 26

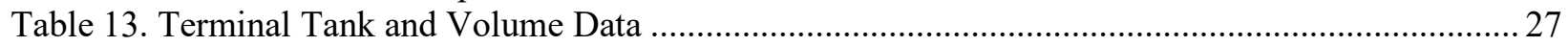

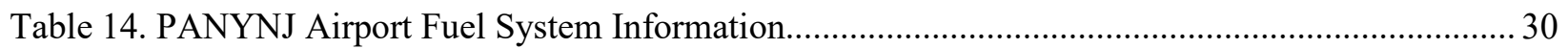




\section{Introduction}

The Port Authority of New York and New Jersey (PANYNJ) sustainability commitment seeks to meet the goals set by the Paris Agreement, with an interim greenhouse gas reduction target of $35 \%$ by 2025 and $80 \%$ by 2050 . PANYNJ is seeking sustainable solutions to reduce carbon emissions for all public forms of transportation, including aviation. Similarly, the global aviation industry adopted the Carbon Offsetting and Reduction Scheme for International Aviation (CORSIA), which seeks to cap net carbon dioxide $\left(\mathrm{CO}_{2}\right)$ aviation emissions at 2020 levels through 2035. Industry has also set a goal of reducing $\mathrm{CO}_{2}$ emissions by $50 \%$ compared to 2005 levels by 2050 .

Sustainable aviation fuel (SAF), made from non-petroleum feedstocks, is a near-term alternative fuel that reduces emissions from air transportation. PANYNJ has long been involved in finding ways to bring SAF to their airports as one near-term opportunity to meet their sustainability goals. This report evaluates the potential for SAF production in the region and identifies logistics for blending SAF with Jet A for delivery to PANYNJ airports. Logistics were reviewed for John F. Kennedy International Airport (JFK), LaGuardia Airport (LGA), Newark Liberty International Airport (EWR), and Teterboro Airport (TEB).

\subsection{SAF Background and Production}

SAF can be produced from non-petroleum-based renewable feedstocks including but not limited to organic fraction of municipal solid waste (MSW), woody biomass, fats/greases/oils, and other biogenic resources. There are also multiple technology pathways approved to produce fuels. ASTM International (ASTM) is a voluntary consensus standards organization composed of industry experts who create, maintain, and continuously update fuel quality specifications and test methods. ASTM D7566 Standard Specification for Aviation Turbine Fuel Containing Synthesized Hydrocarbons dictates fuel quality standards for non-petroleum-based jet fuel and outlines approved SAF-based fuels and the percent allowable in a blend with Jet A. ${ }^{8}$ ASTM D7566 is continuously updated to allow for advancements in technology to produce SAF. Currently, there are seven synthetic paraffinic kerosene (SPK) and synthetic kerosene with aromatics (SKA) fuel categories approved by ASTM, which are summarized in Section 2.1 of this report.

SAF production is in its early stages, with two known commercial producers. World Energy began SAF production in 2016 at their Paramount, California, facility and supplies fuel to Los Angeles International Airport and Ontario International Airport (United Airlines 2019). International producer Neste began supplying SAF to San Francisco International Airport via pipeline from a terminal in 2020 and by truck through a partnership with Avfuel to Telluride Regional Airport in spring 2021 (SFO 2020; Avfuel 2021). Both World Energy and Neste are expanding production capacity. There are also multiple plants under construction. Fulcrum BioEnergy's plant near Reno, Nevada, plans to convert nearly 160,000 tonnes of MSW into a renewable synthetic crude, which will be transported by truck to a Northern California refinery for processing into transportation fuels, including SAF (Fulcrum BioEnergy 2020). Red Rock

\footnotetext{
${ }^{8}$ ASTM D7566 covers SAF-based fuels as well as jet fuels made from other non-petroleum feedstocks such as natural gas and coal.
} 
Biofuels plans to convert 123,000 tonnes of wood waste into 15 million gallons of SAF and renewable diesel (Red Rock Biofuels 2020). Both Gevo and LanzaTech have developed technology to convert alcohol to SAF and have plans for commercial plants, with the latter expecting to start production of an 8-million-gallon facility in Georgia in late 2022. There are likely multiple other domestic and foreign entities developing technology to increase SAF production.

Actual production volumes of SAF are not reported. Renewable Identification Numbers (RINs), the compliance system for the Renewable Fuel Standard, provide an approximation of the market volume of SAF. Figure 1 shows fairly consistent RIN volumes between 2016 and 2018 and increases in 2019 through 2020. At over 4.6 million gallons, SAF represents a small fraction of the U.S. jet fuel consumption of 26 billion gallons in 2019 (EPA 2021b; EIA 2020). RIN generation from 2020 suggests a significant increase in production, with large variability by month (Figure 2). ${ }^{9}$ The generation of RINs fluctuates throughout a year, which may indicate additional producers entering the market, the availability of feedstocks, and market dynamics, as production plants typically produce SAF and renewable diesel.

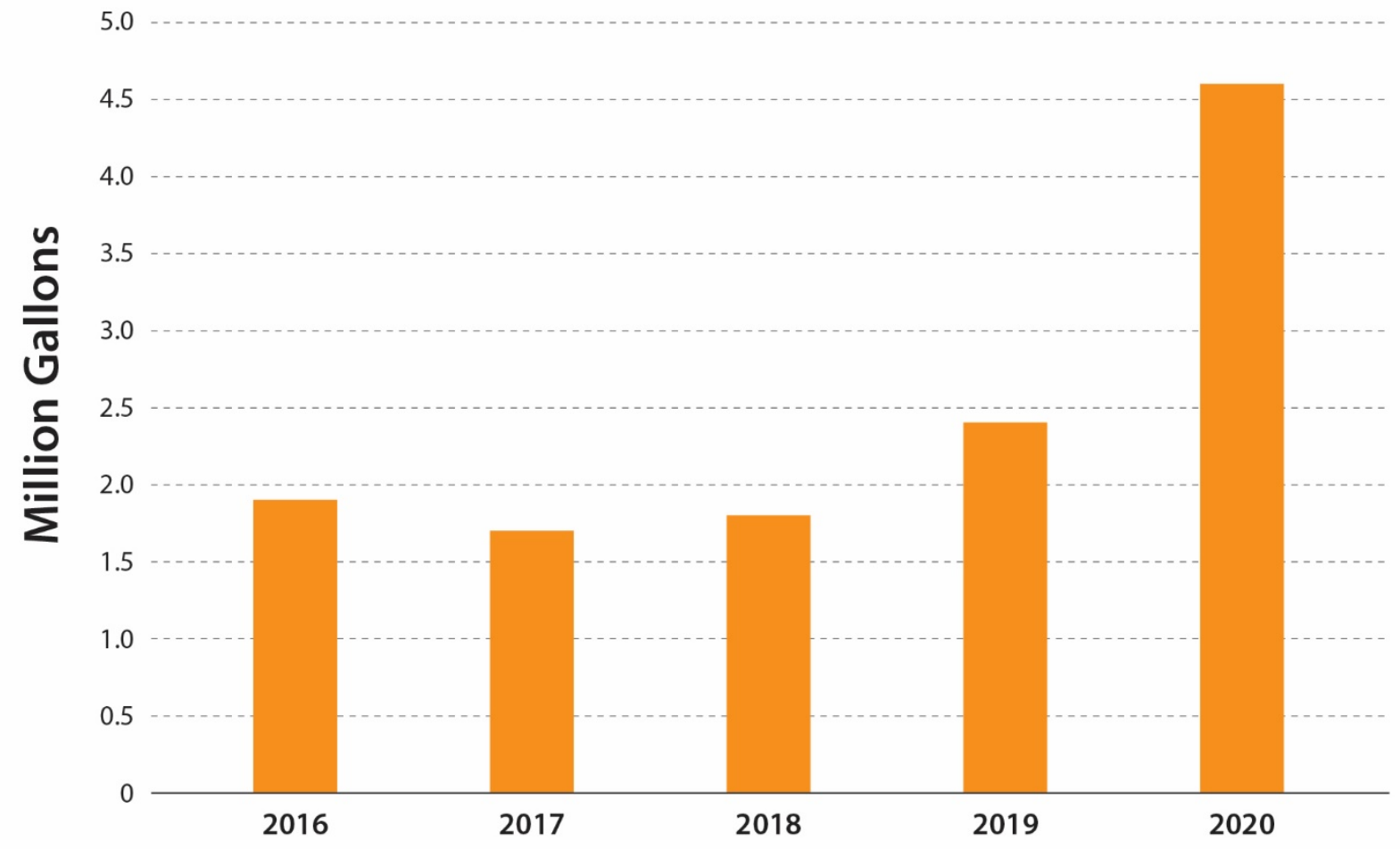

Figure 1. Annual SAF RIN volumes

Source: EPA 2021b

\footnotetext{
${ }^{9}$ The higher RIN generation in some 2020 months were due to an additional producer generating RINs.
} 


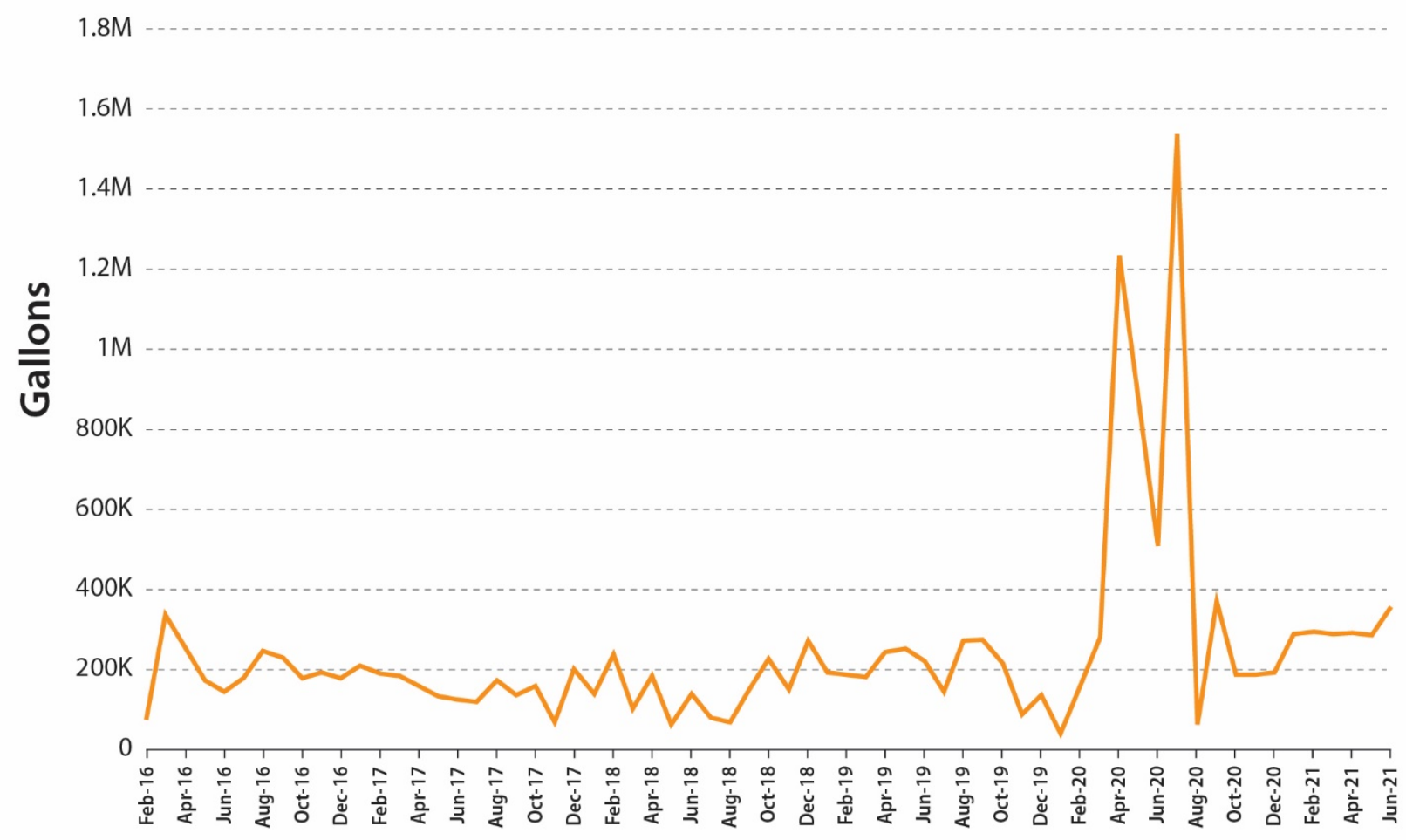

Figure 2. Monthly SAF RIN volumes

Source: EPA 2021b

\section{Potential for Regional SAF Production}

This section reviews both feedstocks within a defined radius of the port district and conversion technology pathways and their associated costs. ${ }^{10}$ Generally, biofuels plants are most economical when they are located near abundant feedstocks. There are multiple potential feedstocks and technology pathways. As production grows, certain feedstocks and pathways may provide economic advantages.

\subsection{Feedstock Evaluation}

A resource assessment was conducted to determine regional SAF feedstock availability (e.g., produced locally and/or transported from other parts of the country). In this analysis, the National Renewable Energy Laboratory (NREL) used the general port district as a location for a potential biorefinery to provide resource availability in close proximity (for resources that are typically not transportable, such as biogas) and within 50-, 100-, and 200-mile radius. The results of this analysis are illustrated in the following text, tables, and figures. The following resources are considered:

- Vegetable oils and byproducts. This analysis includes soybean oil; distillers corn oil (DCO), a byproduct of ethanol production; and crude tall oil, a byproduct of softwood pulping (kraft process) used by paper mills. Other vegetable oils in the United States include canola, corn, cottonseed, sunflower, and safflower, but these are produced at a

\footnotetext{
${ }^{10}$ The port district is an area of jurisdiction within 25 miles of the Statue of Liberty.
} 
much smaller quantity and are used primarily in food-grade applications. As a reference, soybean oil production in the United States was about 11 million tonnes in 2019, corn oil (of which 65\% is DCO) 2.6 million tonnes, and canola oil 733,000 tonnes (ERS 2021). Annual crops such as camelina and pennycress have received attention in recent years but their commercial production is still under development.

- Fats, oils, and greases (FOG) include animal fats (e.g., tallow, white grease, and poultry fat) obtained from slaughterhouse and livestock farm waste, yellow grease (rendered used cooking oil [UCO] generated at commercial and industrial cooking operations), and brown grease (rendered trap/interceptor grease recovered from traps installed in the sewage lines of restaurants/food processing plants and wastewater treatment plants) (Milbrandt et al. 2018). Typically, FOG is not used in its raw form-industries purchase purified material from rendering plants. This analysis excludes edible animal fats, namely lard and edible tallow.

- Municipal solid waste (MSW) is waste collected from residential, institutional, commercial, and some industrial entities. It is assumed that paper/cardboard, yard trimmings, and clean wood would be converted to SAF. Further development of emerging technology pathways could result in using more waste streams from MSW.

- Biogas is the gaseous product of anaerobic digestion, a biological process in which microorganisms break down biodegradable material in the absence of oxygen. Biogas is composed primarily of methane and carbon dioxide, with some other trace elements. Methane is the usable portion of biogas for energy production and its content is typically between $50 \%$ and $70 \%$ of raw biogas. Biogas is an intermediate product generated from various organic sources such as animal manure, food waste, and wastewater.

- Lignocellulosic biomass (woody biomass and crop residues). These resources include forest residues (logging residues and other removable material left after carrying out silviculture operations and site conversions), primary mill residues (wood materials generated at wood mills when round wood products are processed into primary wood products), secondary mill residues (wood scraps and sawdust from woodworking shops), urban wood residues (wood in MSW such as chips and pallets, utility tree trimming and/or private tree companies, and construction and demolition sites), and crop residues (e.g., harvesting residues from corn, wheat, soybeans, cotton, sorghum).

It should be noted that consumption of vegetable oils and FOG is expected to increase substantially in the coming years due to several large renewable diesel plants under construction (e.g., Bakersfield Renewable Fuels in California; CVR Energy Inc. in Wynnewood, Oklahoma; HollyFrontier Corp. in Artesia, New Mexico; HollyFrontier Corp. in Cheyenne, Wyoming; and Ryze Renewables in Las Vegas, Nevada) (Bryan 2021). Additionally, three operational renewable diesel facilities are under expansion (Diamond Green Diesel, REG Geismar LLC, and World Energy) and there are several more proposed plants (Diamond Green Diesel in Port Arthur, Texas; Grön Fuels LLC in Baton Rouge, Louisiana; Marathon Petroleum in Martinez, California; Next Renewable Fuels in Port Westward, Oregon; and Phillips 66's Rodeo Renewed 
in California) (Bryan 2021). ${ }^{11}$ If these facilities are built, they will present significant competition for feedstock for biodiesel, renewable diesel, and SAF producers relying on vegetable oils and FOG.

\subsubsection{Vegetable Oils and Byproducts}

Soybean oil production data in the United States are not available below the regional and state level, as illustrated in Table 1. The region most relevant to the port district is the North and East, which includes Indiana, Kentucky, Maryland, Ohio, Pennsylvania, and Virginia. Together, these states account for $24 \%$ of total U.S. soybean oil production. North Carolina also has oil crushing capacity, and it falls in the South, West, and Pacific region.

Table 1. US Soybean Oil Production by Region in 2019

\begin{tabular}{lc}
\hline Region & Soybean Oil Production in $\mathbf{2 0 1 9}$ (tonnes) \\
\hline Illinois & $1,336,037$ \\
\hline lowa & $2,288,932$ \\
North and East & $2,593,652$ \\
North Central & $1,526,011$ \\
South, West, and Pacific & $1,348,206$ \\
West Central & $1,849,233$ \\
Total & $10,942,071$ \\
\hline
\end{tabular}

Figure 3 illustrates the location of oilseed processing plants where crude soybean oil is produced among other products such as soybean meal and hulls. These facilities supply crude soybean oil to refineries for further processing into a food-grade oil, other industries including biodiesel, and export. Information on the capacity of these facilities was not available, so NREL mapped the county-level production of soybean to provide background information on where the resources are located and give a sense of scale.

Perdue AgriBusiness owns two soybean crushing facilities within the 200-mile radius. The facility in Salisbury, Maryland, can process about 408,000 tonnes of soybeans per year, equivalent to about 73,000 tonnes of soybean oil per year (Freeny 1976). ${ }^{13}$ The facility in Bainbridge, Pennsylvania, has the capacity to process 476,000 tonnes of soybeans per year, which translates into roughly 85,000 tonnes of soybean oil per year (Farm and Dairy 2017). These facilities are within 176 miles and 136 miles from the port district, respectively. The company also owns two other facilities farther away in Chesapeake, Virginia, and Cofield, North Carolina. Cargill Inc. owns two plants farther south in North Carolina. Additional volume of

\footnotetext{
${ }^{11}$ World Energy produces renewable diesel and SAF at the same Los Angeles-area plant.

${ }^{12}$ North and East includes Indiana, Kentucky, Maryland, Ohio, Pennsylvania, and Virginia. North Central includes Michigan, Minnesota, North Dakota, and South Dakota. South, West, and Pacific includes Alabama, Arkansas, California, Georgia, Louisiana, North Carolina, and South Carolina. West Central includes Kansas, Missouri, and Nebraska.

${ }^{13}$ Assuming 10.7 pounds of crude soy oil per bushel of soybeans (https://ussec.org/resources/conversion-table/).
} 
soybean oil could be available from states to the west (e.g., Ohio, Indiana, Illinois). Figure 3 also illustrates the location and capacity of corn ethanol plants as an indicator of where and how much DCO is produced. The three facilities closest to the port district (beyond the 200-mile radius) are in Clearfield, Pennsylvania; Fulton, New York; and Medina, New York. Assuming that these facilities operate at about $84 \%$ capacity, NREL estimated that they produced about $12,000,9,000$, and 7,000 tonnes of DCO in 2019, respectively. As with soybean oil, additional volume of DCO could be available from states farther away (e.g., Ohio, Indiana, Illinois) but higher feedstock transportation costs will be incurred. Figure 3 also shows the location of pulp mills in the region as a reference for where tall oil could be sourced from. There are about 15 mills within a 50-mile radius and 12 more within a 100 -mile radius of the port district. However, information on the type of processing (kraft vs. other chemical vs. mechanical) at these facilities is not available, so NREL is unable to verify whether tall oil is produced on-site. As a reference, tall oil production in the United States is between 500,000-700,000 tonnes annually (Aryan and Kraft 2021).

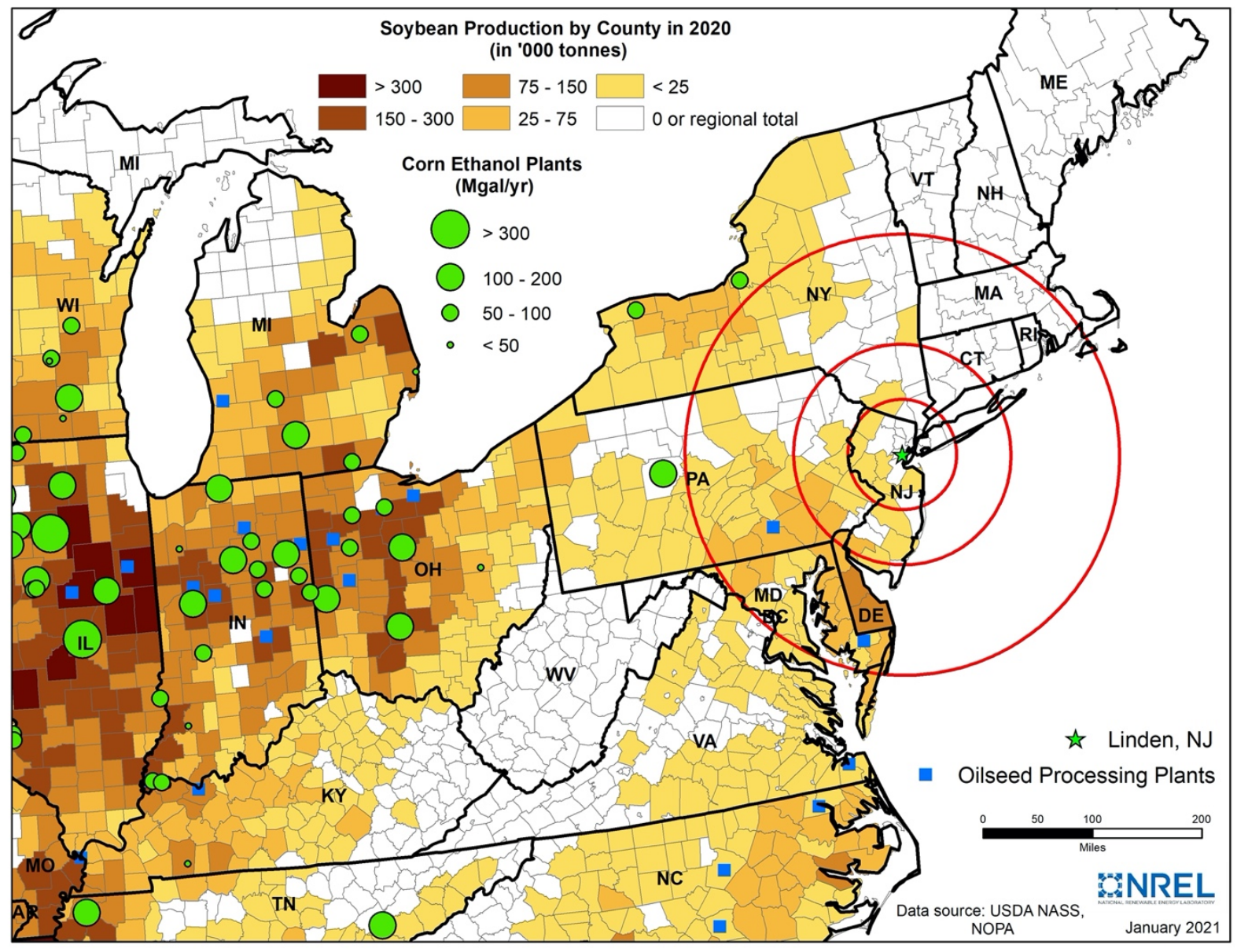

Figure 3. Soybean production by county, oilseed processing facilities, and corn ethanol plants

Note: The red circles illustrate the 50-, 100-, and 200-mile radius from the port district 


\subsubsection{Fats, Oils, and Greases (FOG)}

This section provides a brief description of the FOG collection and disposal logistics. Dedicated UCO and trap grease collection companies, also called haulers, obtain the material from restaurants and other food-processing establishments and dispose of it through various methods including landfills, wastewater treatment plants, rendering plants, incinerators, or anaerobic digesters. Rendering plants either collect UCO and trap grease themselves or receive it from haulers and/or wastewater treatment plants to further process the materials into valuable products and chemicals. Wastewater treatment plants either collect trap grease on-site as part of routine operations (though this is becoming increasingly uncommon as the grease can block sewage lines if it is not removed upstream at grease traps) or receive it from haulers. In addition to UCO and trap grease, rendering plants also collect waste from slaughterhouses and livestock farms to generate various products, including animal fats. As mentioned earlier, FOG is not typically used in its raw form-industries purchase purified material from rendering plants.

Figure 4 illustrates the geographic distribution of FOG production in the region. The animal fat rendering locations also indicate rendering of UCO and trap grease at those sites. NREL does not have data on the quantity of these materials processed on-site, and therefore mapped their generation at the city level. Also, some of these materials are landfilled, incinerated, anaerobically digested, or composted, and therefore the amount that is processed at rendering plants would not represent the total potential.

A rendering plant in Newark, New Jersey, owned by Darling Ingredients Inc. (DAR PRO Solutions 2021) is the closest rendering plant in the area, and NREL estimates that it processes about 1,653 tonnes of tallow and choice white grease per year. This plant also collects and processes UCO and trap grease into yellow and brown grease, respectively, but NREL was unable to estimate that quantity. It should be noted, however, that the company uses these materials in their biofuels facilities: It owns and operates two biodiesel plants and one renewable diesel plant (DAR PRO Solutions 2021).

Two other large companies that collect and utilize FOG in the area are Liquid Environmental Solutions and Mahoney Environmental. No local processing facilities are evident from the companies' websites, but it appears that they collect material in the region and transport it to their processing facilities in nearby states (e.g., Maryland, Pennsylvania, Tennessee, and North Carolina) (Mahoney Environmental 2021; Liquid Environmental Solutions 2021). Neste, a producer of renewable diesel and SAF, acquired Mahoney Environmental in early 2020 (Neste Corp. 2020). This acquisition allows Neste to expand its feedstock supply in North America.

Table 2 illustrates NREL's estimate for FOG production within 50-, 100-, and 200-mile radius of the port district. It should be noted that the UCO and trap grease generation indicates the resource potential in the area, not the quantity collected and processed by local renderers. As mentioned earlier, these materials are utilized in various ways or disposed. Although animal fat rendering locations within the 200-mile radius or just outside of it (e.g., Virginia, Pennsylvania) show a smaller quantity for this type of FOG, that may not be the case for yellow and brown grease. Further analysis on the ground would provide more detailed information on the 
availability of these resources in the area. For example, the State of New Jersey has compiled a list of renderers and recyclers in the area. ${ }^{14}$

Table 2. Estimated FOG Production Within 50-, 100-, and 200-Mile Radius of the Port District

\begin{tabular}{ccc}
\hline Radius & Animal Fats (tonnes/yr) & UCO and Trap Grease (tonnes/yr) \\
\hline 50 miles & 1,650 & 175,000 \\
100 miles & 5,500 & 290,000 \\
200 miles & 106,000 & 488,000 \\
\hline
\end{tabular}

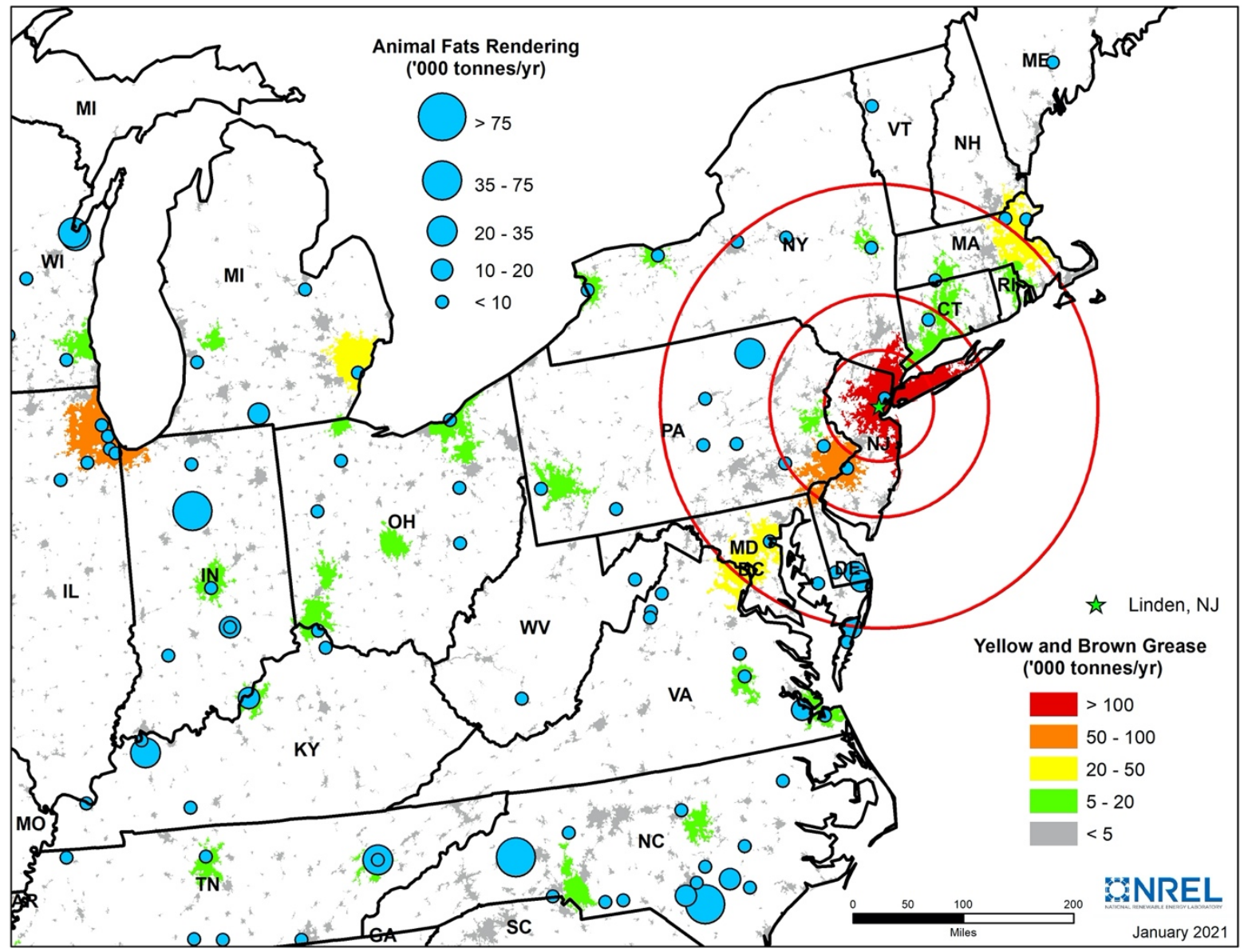

Figure 4. FOG production

Note: The red circles illustrate the 50-, 100-, and 200-mile radius from the port district

\subsubsection{Municipal Solid Waste (MSW)}

MSW generation by county in 2019 was estimated using U.S. Census Bureau population estimates that year and the U.S. Environmental Protection Agency's national average per-capita waste generation rate of 4.9 pounds per person per day (EPA 2021a). Regional composition data indicates that paper/cardboard constitutes about $21 \%$, yard waste $-6 \%$, and wood $-6 \%$ of total

\footnotetext{
${ }^{14}$ https://www.nj.gov/dep/dshw/recycling/renderers_list.htm
} 
MSW (T\&M Associates 2015). Using these fractions and assuming that half of the wood waste is clean and the rest is treated thus unsuitable for conversion applications, NREL estimated that about 4 million tonnes of MSW were generated within a 50-mile radius, about 7.4 million tonnes within a 100-mile radius, and about 12.3 million tonnes within a 200 -mile radius of the port district in 2019. It should be noted that there are local variations in waste generation rates and this analysis should be viewed as approximate. Figure 5 illustrates the geographic distribution of these resources. Further development of emerging technology pathways could result in using more waste streams from MSW.

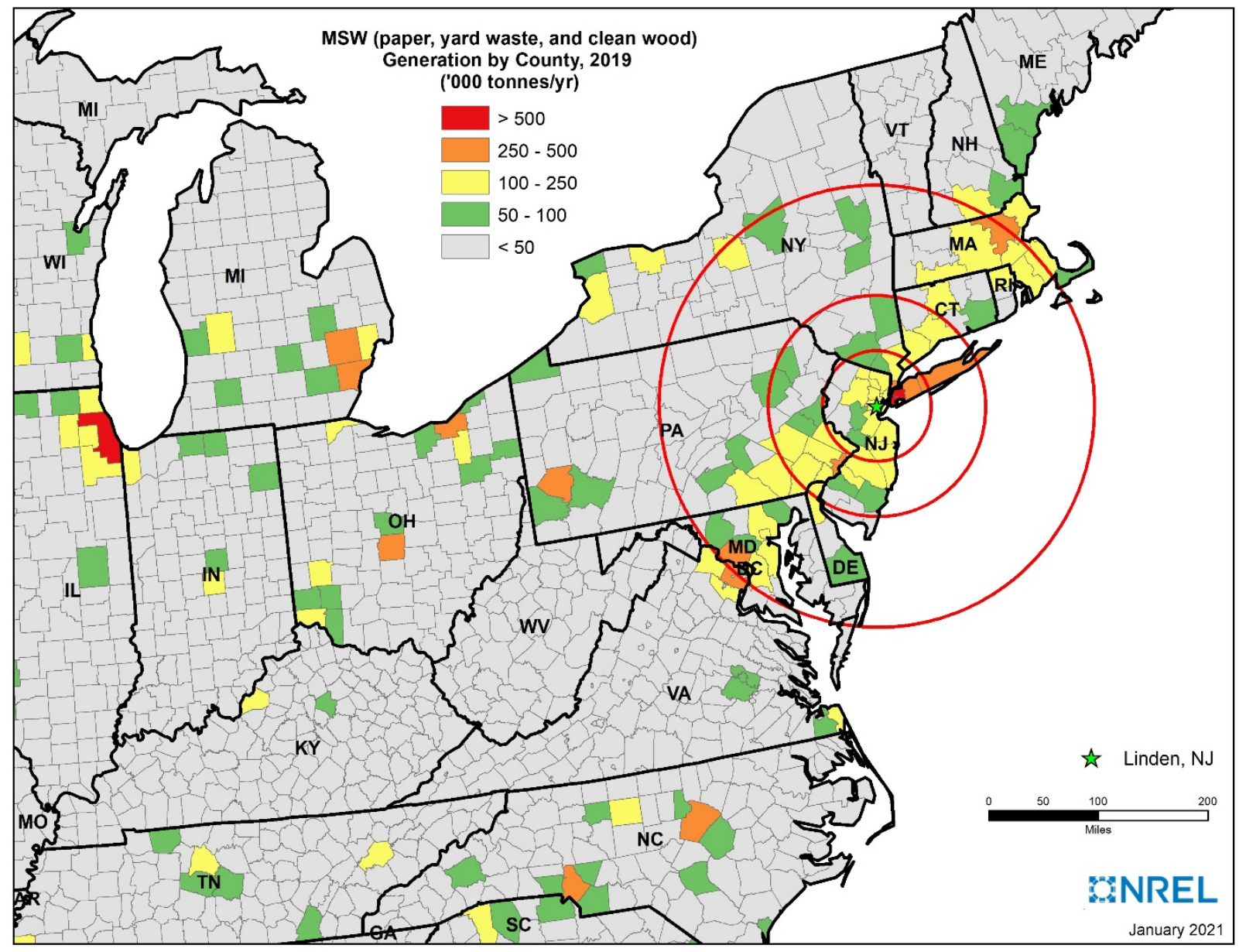

Figure 5. MSW (paper, yard waste, and clean wood) generation by county in 2019

Note: The red circles illustrate 50-, 100-, and 200-mile radius from the port district

\subsubsection{Biogas}

Figure 6 illustrates the methane generation potential from food waste (by county) and wastewater (on-site) near the port district. The wastewater treatment plants in Linden, Elizabeth, and Rahway are the closest facilities, and all three of them use anaerobic digestion for wastewater sludge treatment and reduction. Although the estimated methane potential is larger for the plants in Newark and Sayreville, to the best of our knowledge these plants are not utilizing anaerobic digestion. NREL estimates that about 3,800 tonnes of methane could be produced by Elizabeth's 
wastewater treatment plant, about 1,400 tonnes by Rahway's plant, and about 500 tonnes by Linden's plant. The methane production potential could be increased by co-digesting sludge with food waste (and/or FOG) sourced locally and/or from nearby counties, especially New York, Queens, and Kings, where a large quantity of food waste is generated.

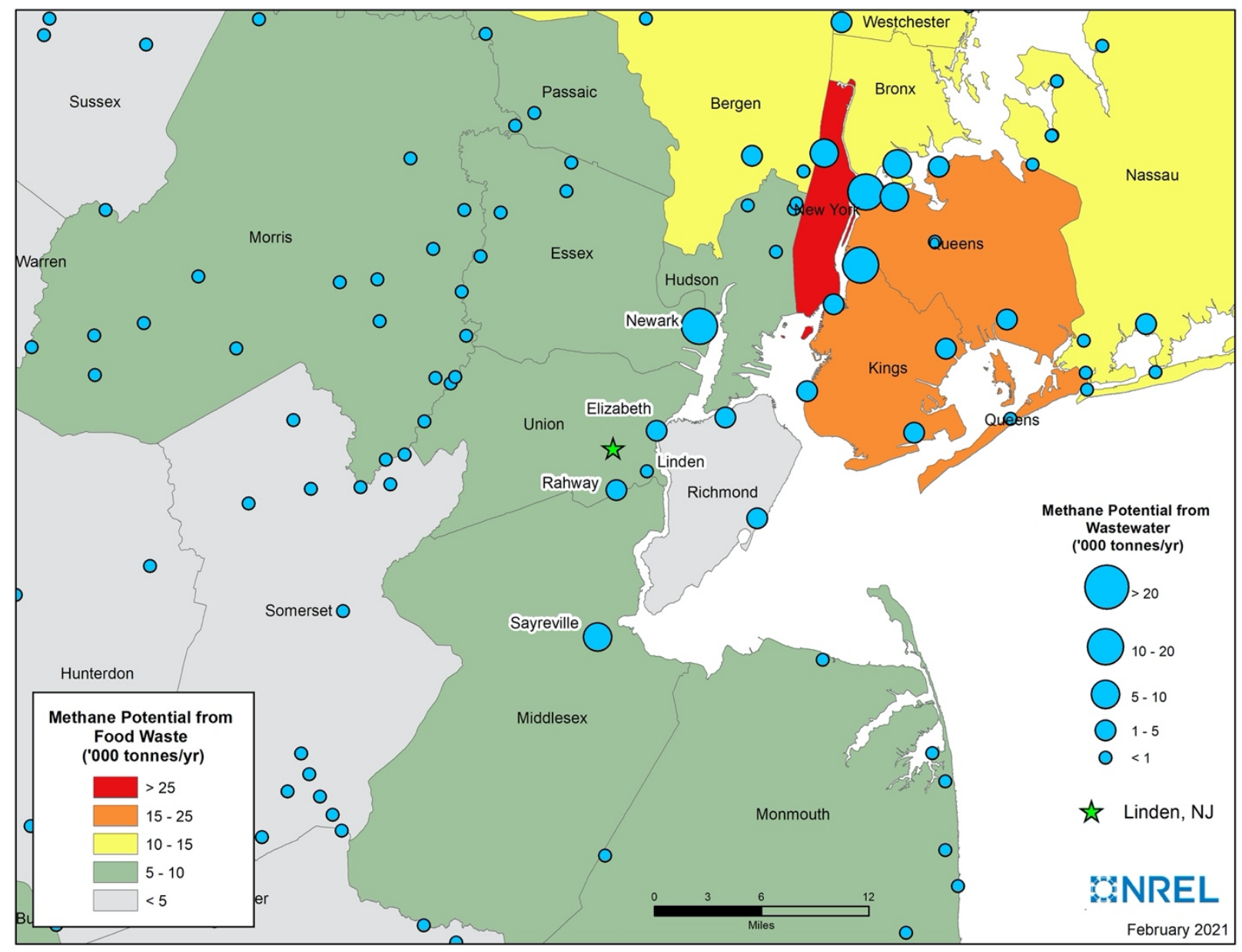

Figure 6. Methane generation potential from wastewater and food waste near the port district

\subsubsection{Lignocellulosic Biomass}

Figure 7 illustrates the crop residues and woody biomass (logging residues, primary and secondary mill residues, and urban wood waste) potential by county in the region, and Table 3 summarizes that potential within 50-, 100-, and 200-mile radius of the port district. These biomass resources could be transported from other states with abundant potential such as Ohio, Indiana, parts of North Carolina for crop residues, or Maine and North Carolina for woody biomass, but higher feedstock transportation costs will be incurred. 
Table 3. Estimated Crop Residues and Woody Biomass Potential Within 50-, 100-, and 200-Mile Radius of the Port District

\begin{tabular}{ccc}
\hline Radius & Crop Residues (dry tonnes/yr) & Woody Biomass (dry tonnes/yr) \\
\hline 50 miles & 75,000 & $2,542,000$ \\
100 miles & 426,000 & $4,504,000$ \\
200 miles & $2,900,000$ & $9,610,000$ \\
\hline
\end{tabular}

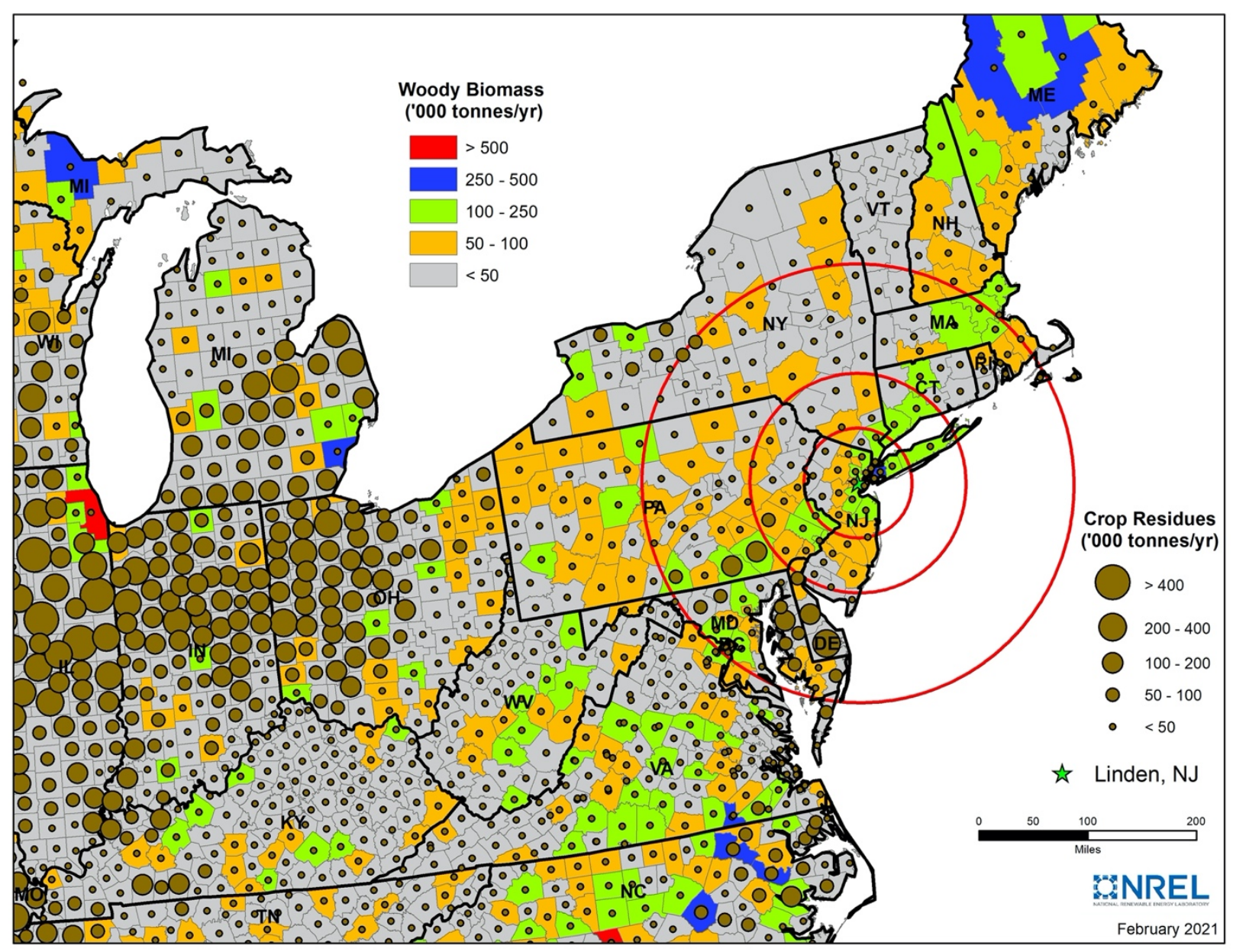

Figure 7. Crop residues and woody biomass potential by county

Note: The red circles illustrate 50-, 100-, and 200-mile radius of the port district.

\subsection{Techno-Economic Analysis}

In addition to resource analysis, NREL evaluated and compared the economics of a new, local production facility from multiple feedstocks. NREL performed techno-economic analysis (TEA) using data from regional feedstock availability, based on the resources of interest including organic wet wastes (e.g., grease and fats, manure, food waste, and sludge), oil crops, woody biomass, and crop residues. The TEA used the feedstock to determine which ASTM-approved pathway to use for the analysis. 
SAF comes in two varieties: SPK and SKA. ${ }^{15}$ SPK and SKA fuels have to be blended up to $50 \%$ with conventional commercial and military jet (or aviation turbine) fuel. SKA fuels have the potential to blend slightly higher than $50 \%$. Blending of SPK fuels is required because they lack sufficient aromatic hydrocarbons, which are present in conventional jet fuel. Although aromatic hydrocarbons are limited in jet fuel to prevent smoke formation during combustion, a minimum aromatic content is needed to cause elastomer swell in aircraft fuel systems and increase fuel density. Currently, there are seven approved alternative jet fuel pathways approved by ASTM. The approved pathways are summarized in Table 4 and additional details of each pathway are available in Appendix A. SAF must be blended with conventional jet fuel (from $10 \%-50 \%$ depending on the annex, shown in Table 4). While SAF production volumes remain low, a blend limit does not impact SAF development. However, the blend level might eventually increase to $100 \%$ with newer engine designs. The Fischer-Tropsch (FT)-containing aromatics are the only ASTM-approved pathway with SKA. This pathway technology is named FT-SP/A, as the product contains a fraction of aromatics mixed with SPK.

Table 4. Summary of Blending Limitations and Feedstocks for Seven ASTM-Approved Pathways

\begin{tabular}{llll}
\hline Pathway & Approved Name & $\begin{array}{l}\text { Blending } \\
\text { Limitation }\end{array}$ & Feedstocks \\
\hline $\begin{array}{l}\text { Fischer-Tropsch synthetic } \\
\text { paraffinic kerosene }\end{array}$ & $\begin{array}{l}\text { FT-SPK, ASTM D7566 } \\
\text { Annex A1, 2009 }\end{array}$ & $50 \%$ & $\begin{array}{l}\text { Municipal solid waste, } \\
\text { agricultural and forest } \\
\text { wastes, energy crops }\end{array}$ \\
$\begin{array}{l}\text { Hydroprocessed esters and } \\
\text { fatty acids (HEFA) }\end{array}$ & $\begin{array}{l}\text { HEFA-SPK, ASTM } \\
\text { D7566 Annex A2, 2011 }\end{array}$ & $50 \%$ & $\begin{array}{l}\text { Oil-based feedstocks (e.g., } \\
\text { jatropha, algae, camelina, } \\
\text { and yellow grease) }\end{array}$ \\
$\begin{array}{llll}\text { Hydroprocessed fermented } \\
\text { sugars (HFS) to synthetic } \\
\text { isoparaffins (SIP) }\end{array}$ & $\begin{array}{l}\text { HFS-SIP, ASTM D7566 } \\
\text { Annex A3, 2014 }\end{array}$ & $10 \%$ & Sugars \\
\hline $\begin{array}{l}\text { FT-SPK with aromatics } \\
\begin{array}{l}\text { Alcohol-to-jet synthetic } \\
\text { paraffinic kerosene }\end{array}\end{array}$ & $\begin{array}{l}\text { FT-SPK/SKA, ASTM } \\
\text { D7566 Annex A4, 2015 }\end{array}$ & $50 \%$ & Same as A1 \\
$\begin{array}{l}\text { Catalytic hydrothermolysis } \\
\text { synthesized kerosene }\end{array}$ & $\begin{array}{l}\text { CH-SK or CHJ, ASTM } \\
\text { D7566 Annex A6, 2020 }\end{array}$ & $50 \%$ & $\begin{array}{l}\text { Fatty acids, fatty acid } \\
\text { esters, or lipids from fats, } \\
\text { oils, and greases }\end{array}$ \\
\hline $\begin{array}{l}\text { Hydrocarbon-hydroprocessed } \\
\text { esters and fatty acids }\end{array}$ & $\begin{array}{l}\text { HC-HEFA-SPK, ASTM } \\
\text { D7566 Annex A7, 2020 }\end{array}$ & $10 \%$ & Algal oil \\
\hline
\end{tabular}

\subsubsection{Techno-Economic Analysis Methodology}

FT-SPK, HEFA-SPK, and HFS-SIP were selected for this study based on available regional biomass feedstocks. NREL develops and maintains TEA models that describe the process and production economics of conceptual biochemical conversion pathways to biofuels and bioproducts. Data were generated with Aspen Plus process simulation using a set of conversion

\footnotetext{
${ }^{15}$ This report is focused on SAF. SPK and SKA fuels could also be made from other non-petroleum, non-renewable
} feedstocks such as natural gas or coal. 
parameters, material and energy balances, and flow rates. ${ }^{16}$ These data were used to size and cost process equipment and compute raw material and other operating costs. Based on a discounted cash flow rate of return, the analysis determined the minimum fuel selling price (MFSP) required to obtain a net present value of zero for a $10 \%$ internal rate of return.

It should be emphasized that the TEA outputs carry some uncertainty related to the assumptions made for capital and raw material costs. Without a detailed understanding of the basis behind it, the absolute computed cost values have limited relevance. Any new plant could have different capital and input costs that would impact the overall costs and economics that determine if a plant is viable. Also, all available feedstocks would likely not go to a single plant; the TEA shows the potential production and MFSP. The TEA outputs are best used to compare different pathways and feedstocks against one another.

The economic analysis includes a conceptual process design that enables development of a detailed process flow diagram (based on research or commercial data), rigorous material and energy balance calculations (via a commercial simulation tool, Aspen Plus), capital and project cost estimations (via an in-house model using spreadsheets), a discounted cash flow economic model, and the calculation of an MFSP (Davis et al. 2013; Tao et al. 2017). The operating expense calculation for the designed facility is based on material and energy balance calculations using Aspen Plus process simulations. All costs are adjusted to 2017 U.S. dollars (2017\$) using the Plant Cost Index from Chemical Engineering, the Industrial Inorganic Chemical Index from SRI Consulting, and the labor indices provided by the U.S. Department of Labor Bureau of Labor Statistics (Chemical Engineering 2021; SRI Consulting 2008; Bureau of Labor Statistics 2021).

The overall process efficiency (or on-stream factor) is assumed to be $90 \%(7,884$ operating hours per year), consistent with other TEA design reports (Davis et al. 2011; Dutta et al. 2011). ${ }^{17}$ Salaries for personnel are inflated to 2017\$ (Bureau of Labor Statistics 2021). Sixty percent of the total salaries are added for labor burden, and $2.0 \%$ of the total installed capital was designated for maintenance (which includes cleaning expenses) (Davis et al. 2012). Property insurance and taxes account for $1.5 \%$ of the total capital investment (Davis et al. 2012). The federal corporate tax rate used in our analysis is $35 \%$, and U.S. income tax was averaged over the plant life, calculated on a per-gallon basis. The amount of income tax to be paid by a potential fuel producer varies annually due to changes in the volume of product produced and the allowable depreciation deduction.

After the total capital investment, variable operating costs, and fixed operating costs are determined, a discounted cash flow rate of return analysis is typically used to determine MFSP. The discounted cash flow analysis was calculated by iterating the selling cost of the product until the net present value of the project is zero with a $10 \%$ internal rate of return. The analysis requires that the discount rate, depreciation method, income tax rates, plant life, and construction startup duration be specified. The discounted cash flow assumes $40 \%$ equity financing with a loan interest at $8 \%$ for 10 years. Working capital is assumed to be $5 \%$ of the fixed capital investment. The plant is assumed to take 3 years to construct, with a half of a year spent on

\footnotetext{
${ }^{16} \mathrm{https}: / /$ www.aspentech.com/en

${ }_{17}$ On-stream factor is the time a plant is operating.
} 
startup. The Internal Revenue Service Modified Accelerated Cost Recovery System (MACRS) was used because it offered the shortest recovery period and largest tax deductions, consistent with several NREL design reports. The steam production plants depreciate over a 20-year recovery period and all other properties depreciate in a 7-year recovery period. The plant's life is assumed to be 30 years. Detailed methods are described in previously published NREL design reports (Davis 2013; Dutta et al. 2011; Humbird et al. 2011; Aden et al. 2002).

Total capital investment (TCI) per annual gge of fuel is also listed in the tables of this section. This parameter illustrates challenges on capital investment. For example, although MSFP for both MSW and woody biomass to SAF pathways are low by comparison to the other technologies, the TCI/annual gge of fuel produced are high. This indicates significant capital investment would be required for constructing the biorefinery facilities. This partially explains why there is limited investment being made today on these technologies even though they are cost competitive with economy of scales. Technology challenges and risks for large scale commercialization for individual pathways have not been explored extensively in this report.

\subsubsection{Vegetable Oils; Fats, Oils, and Greases; and Used Cooking Oil SAF Production Estimates}

Soybean oil is not available in the port district but is available within 200 miles at volumes sufficient to support a plant. Assuming a soybean price of $\$ 0.64 / \mathrm{kg}$, the MFSP of the hydrocarbon via the HEFA-SPK pathway is estimated at approximately \$3.74/gallon of gasoline equivalent (gge) (Table 5). The conversion cost without considering feedstock cost would be about $\$ 1.25 /$ gge. This means that SAF could be cost-competitive with conventional jet fuel with low-cost soybean oil. Annual SAF production is estimated to be 26 million gallons of gasoline equivalent (MMgge), whereas total hydrocarbon (HC) production is about $41 \mathrm{MMgge} / \mathrm{yr}$.

Table 5. HEFA Soybean SAF Production and Minimum Fuel Selling Price

\begin{tabular}{llllllll}
\hline Radius & $\begin{array}{l}\text { Soybean } \\
\text { Oil } \\
\text { (tonnes/ } \\
\text { yr) }\end{array}$ & $\begin{array}{l}\text { SAF } \\
\text { Production } \\
\text { via Annex-2 } \\
\text { (MMgge/yr) }\end{array}$ & $\begin{array}{l}\text { SAF } \\
\text { Production } \\
(\mathbf{1}, \mathbf{0 0 0} \\
\text { tonnes) }\end{array}$ & $\begin{array}{l}\text { Total HC } \\
\text { Production } \\
\text { (MMgge/yr) }\end{array}$ & $\begin{array}{l}\text { Total HC } \\
\text { Production } \\
\text { (tonnes) }\end{array}$ & $\begin{array}{l}\text { TCI } \\
\text { per } \\
\text { Annual } \\
\text { gge }\end{array}$ & $\begin{array}{l}\text { MFSP } \\
\text { of Total } \\
\text { HC } \\
\text { (\$/gal) }\end{array}$ \\
\hline 200 miles & 158,000 & 26 & 73 & 41 & 115,000 & $\$ 5.2$ & $\$ 3.74$ \\
\hline
\end{tabular}

Table 6 shows the HEFA-SPK jet fuel production potential from FOG within 50-, 100-, and 200mile radius. Assuming a FOG price of $\$ 0.47 / \mathrm{kg}$ (Directory RNM 2018), the MFSP is estimated at about $\$ 4.48-\$ 38.39 /$ gge. The conversion cost without considering feedstock cost would be about $\$ 2$ /gge for the 200-mile scenario, which also means that SAF could be cost-competitive with conventional jet fuel with both low feedstock costs and large conversion facility sizes. However, a significant investment would be required by as indicated by the TCI. 
Table 6. HEFA FOG SAF Production and Minimum Fuel Selling Price

\begin{tabular}{llllllll}
\hline Radius & $\begin{array}{l}\text { Animal } \\
\text { Fats } \\
\text { (tonnes } \\
\text { /yr) }\end{array}$ & $\begin{array}{l}\text { SAF } \\
\text { Production } \\
\text { via Annex-2 } \\
\text { (MMgge/yr) }\end{array}$ & $\begin{array}{l}\text { SAF } \\
\text { Production } \\
\text { (tonnes) }\end{array}$ & $\begin{array}{l}\text { Total HC } \\
\text { Production } \\
\text { (MMgge/yr) }\end{array}$ & $\begin{array}{l}\text { Total HC } \\
\text { Production } \\
\text { (tonnes) }\end{array}$ & $\begin{array}{l}\text { TCI } \\
\text { per } \\
\text { Annual } \\
\text { gge }\end{array}$ & $\begin{array}{l}\text { MFSP of } \\
\text { Total HC } \\
\text { (\$/gal) }\end{array}$ \\
\hline 50 miles & 1,650 & 0.3 & 730 & 0.3 & 1,137 & $\$ 58.2$ & $\$ 38.39$ \\
\hline 100 miles & 5,500 & 1 & 2,439 & 1 & 3,796 & $\$ 31.2$ & $\$ 15.54$ \\
\hline 200 miles & 106,000 & 17 & 55,109 & 20 & 73,278 & $\$ 7.9$ & $\$ 4.45$ \\
\hline
\end{tabular}

There is sufficient UCO feedstock in the local area. Table 7 shows the HEFA-SPK jet fuel production potential from UCO within 50-, 100-, and 200-mile radius. The feedstock price used in this evaluation was $\$ 0.55 / \mathrm{kg}$ (Directory RNM 2018). The MFSP is estimated at $\$ 3.07-$ $\$ 3.44 /$ gge. As with FOG, SAF could be cost-competitive with conventional jet fuel with low-cost UCO feedstocks. Annual SAF production is estimated from 33-92 MMgge/yr.

Table 7. HEFA UCO SAF Production Potential and Minimum Fuel Selling Price

\begin{tabular}{llllllll}
\hline Radius & $\begin{array}{l}\text { UCO and } \\
\text { Trap } \\
\text { Grease } \\
\text { (tonnes/yr) }\end{array}$ & $\begin{array}{l}\text { SAF } \\
\text { Production } \\
\text { via Annex-2 } \\
\text { (MMgge/yr) }\end{array}$ & $\begin{array}{l}\text { SAF } \\
\text { Production } \\
\text { (tonnes) }\end{array}$ & $\begin{array}{l}\text { Total HC } \\
\text { Production } \\
\text { (MMgge/yr) }\end{array}$ & $\begin{array}{l}\text { Total HC } \\
\text { Production } \\
\text { (tonnes) }\end{array}$ & $\begin{array}{l}\text { TCI } \\
\text { per } \\
\text { Annual } \\
\text { gge }\end{array}$ & $\begin{array}{l}\text { MFSP } \\
\text { of Total } \\
\text { HC } \\
\text { (\$/gal) }\end{array}$ \\
\hline 50 miles & 175,000 & 33 & 90,982 & 43 & 122,723 & $\$ 4.9$ & $\$ 3.44$ \\
\hline 100 miles & 290,000 & 55 & 150,768 & 72 & 203,366 & $\$ 4.0$ & $\$ 3.23$ \\
\hline 200 miles & 488,000 & 92 & 253,842 & 121 & 342,223 & $\$ 3.2$ & $\$ 3.07$ \\
\hline
\end{tabular}

Figure 8 shows impacts from variations of feedstock costs, plant scales, and types of oil feedstocks. Feedstock availability impacts cost most significantly. As an example, FOG at a 100mile radius does not perform well due to low availability, and the MFSP is high without accounting for feedstock costs.

Hydrogen demand for the HEFA pathways ranges from 84-112 g hydrogen per gge of hydrocarbon fuel product, depending on the feedstock types. For instance, soybean and UCO uses less hydrogen per gge of hydrocarbon than that is for animal fats (FOG). Fossil derived hydrogen would have an adverse impact on greenhouse gas emission of the HEFA processes. Renewable hydrogen improves GHG emission, however, might trade off with high cost and limited availability. 


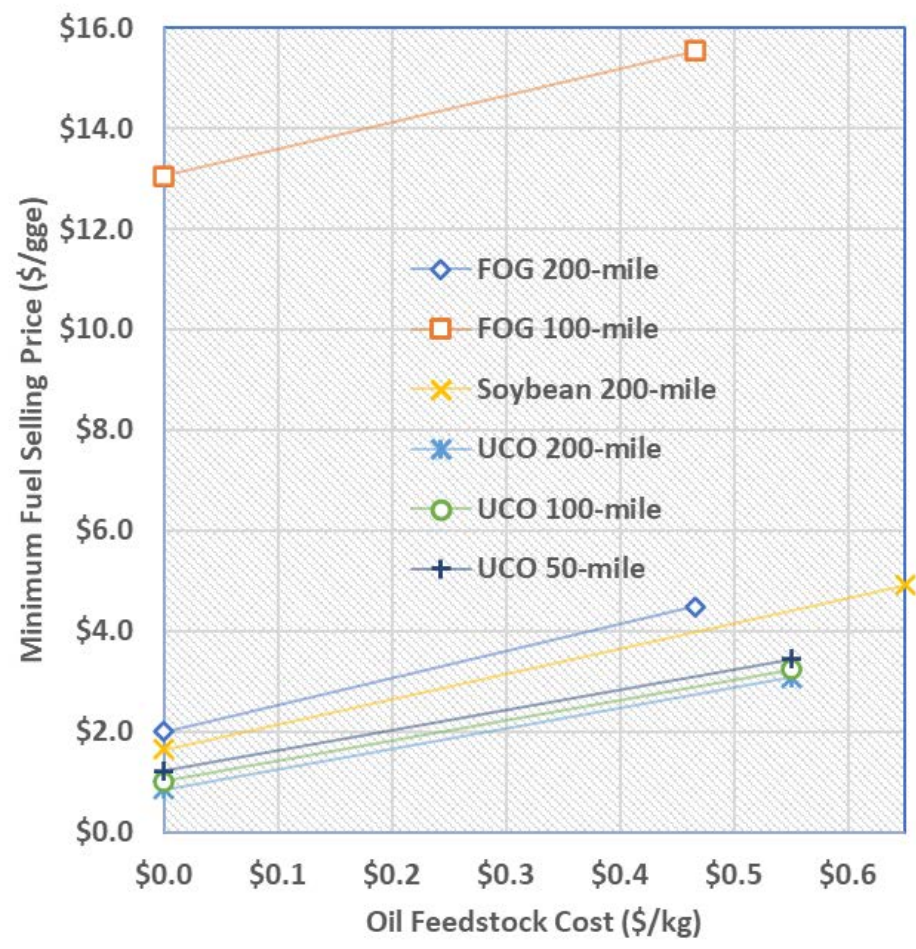

Figure 8. Cost impacts from variations of feedstock costs, plant scales, and types of oil feedstocks

\subsubsection{Municipal Solid Waste SAF Production Estimates}

Table 8 shows the FT-SPK jet fuel production potential from select organic MSW material within 50-, 100-, and 200-mile radius of a targeted location. Assuming a centralized conversion facility, hydrocarbon production potential is estimated at about 101-310 MMgge/yr for 50-, 100, and 200-mile-radius scenarios. These large numbers reflect the high population in the area generating the feedstock. The key assumptions for cost estimations are:

- The price for select organic MSW is approximated with local landfill tipping fees since these wastes are conventionally disposed in MSW landfills. The average landfill tipping fee in New Jersey is estimated at $\$ 90 /$ tonne and in New York at $\$ 75 /$ tonne, or an average of $\$ 82.5 /$ tonne (EREF 2020). The baseline feedstock cost is assumed $\$ 88 /$ dry tonne, and the sensitivity analysis assumes feedstock cost ranging from $\$ 0$ to $\$ 132$ per dry tonne (Figure 9).

- Feedstock composition for the MSW material considered here (paper/cardboard, yard trimmings, and clean wood) are similar to woody biomass feedstocks, but the TEA model accounts for about $10 \%$ yield loss when using MSW.

- No transportation cost is considered for each 50-, 100-, and 200-mile-radius scenario.

- The model assumes that the MSW waste streams are sorted prior to delivery to the plant gate.

The MFSP of the hydrocarbon via FT-SPK pathway is estimated at about \$0.50-\$3.5/gge, depending on feedstock costs and plant scale defined by each radius scenario (Figure 9). This means that SAF could be cost-competitive with conventional jet fuel wholesale prices when MSW price is about $\$ 88$ per dry tonne or less if there are no additional transportation costs. This 
is mainly due to the large amount of MSW available even within a 50-mile radius scenario, implying a high-volume, low-cost SAF opportunity. This study used $\$ 88$ per dry tonne, resulting in an MFSP ranging from \$2.24-\$2.53/gge. Another consideration is the high TCI indicating a significant capital investment is necessary which may explain the limited investment in MSW to SAF facilities. Note that the technology required to sort out plastics is quite complex and costly if implemented into a conventional materials recovery facility. To address the uncertainty on feedstock cost, sensitivity analysis is performed with cost range from $\$ 0$ to $\$ 132 /$ tonne on sorted MSW with paper, yard, waste, and clean wood fraction (Figure 9).

Table 8. Select Organic MSW SAF Production Potential and Minimum Fuel Selling Price

\begin{tabular}{llllllll}
\hline Radius & $\begin{array}{l}\text { MSW (paper, } \\
\text { yard waste, } \\
\text { and clean } \\
\text { wood) } \\
\text { (tonnes/yr) }\end{array}$ & $\begin{array}{l}\text { SAF } \\
\text { Production } \\
\text { via Annex-1 } \\
\text { (MMgge/yr) }\end{array}$ & $\begin{array}{l}\text { SAF } \\
\text { Production } \\
\mathbf{( 1 , 0 0 0} \\
\text { tonnes) }\end{array}$ & $\begin{array}{l}\text { Total HC } \\
\text { Production } \\
\text { (MMgge/yr) }\end{array}$ & $\begin{array}{l}\text { Total HC } \\
\text { Production } \\
(\mathbf{1 , 0 0 0} \\
\text { tonnes) }\end{array}$ & $\begin{array}{l}\text { TCI } \\
\text { per } \\
\text { Annual } \\
\text { gge }\end{array}$ & $\begin{array}{l}\text { MFSP } \\
\text { of } \\
\text { Total } \\
\text { HC } \\
\text { (\$/gal) }\end{array}$ \\
\hline 50 miles & $4,000,000$ & 101 & 312 & 226 & 716 & $\$ 9.4$ & $\$ 2.53$ \\
\hline 100 miles & $7,400,000$ & 187 & 418 & 532 & 1,325 & $\$ 8.3$ & $\$ 2.35$ \\
\hline 200 miles & $12,300,000$ & 310 & 959 & 694 & 2,203 & $\$ 7.6$ & $\$ 2.24$ \\
\hline
\end{tabular}

MSW

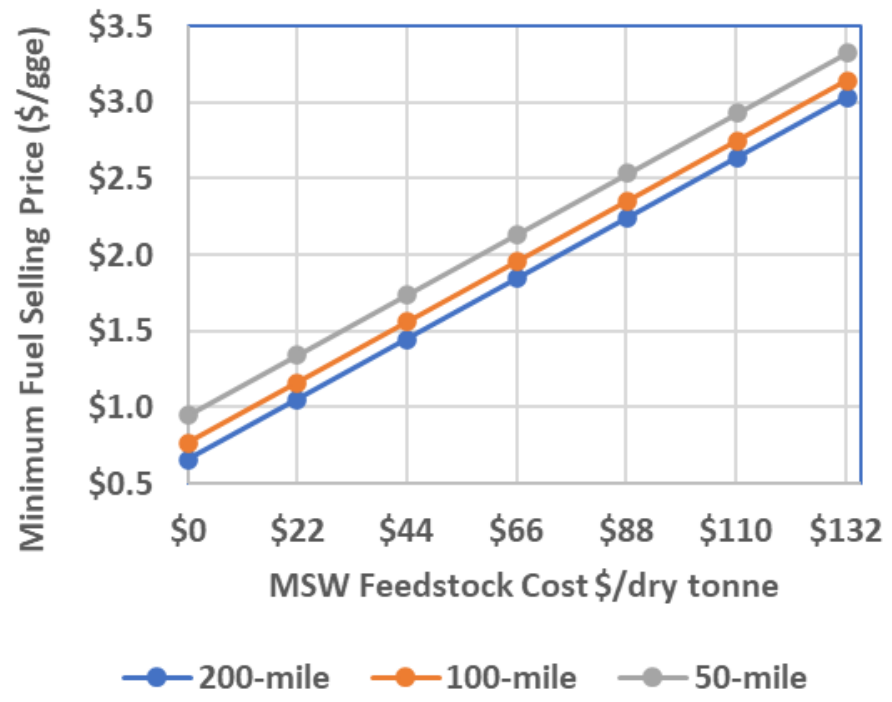

Figure 9. Cost variations from three scenarios and MSW feedstock prices

\subsubsection{Woody Biomass SAF Production Estimates}

Table 9 shows the FT-SPK jet fuel production potential from woody biomass within 50-, 100-, and 200-mile radius of a targeted location. Assuming a centralized conversion facility, hydrocarbon production potentials from these woody biomass feedstocks are estimated at about 71, 126, and 269 MMgge annually for the radius scenarios, respectively. 
The baseline woody biomass price used in this study is $\$ 88$ per dry tonne and the sensitivity analysis assumes feedstock cost ranging from $\$ 44$ to $\$ 110$ per dry tonne (US DOE 2016) (Figure 10). The MFSP is estimated at about $\$ 0.5-\$ 2.5 /$ gge, depending on feedstock prices and plant scale defined by each radius scenario. This means that SAF could be cost-competitive with conventional jet fuel wholesale prices when woody biomass price is about $\$ 88$ per dry tonne or less. The amount of available woody biomass feedstocks are significant, representing a great SAF production opportunity, similar to MSW. However, the high TCI indicates a significant capital investment is necessary which may explain the limited investment in woody biomass to SAF facilities.

Table 9. Woody Biomass SAF Production Potential and Minimum Fuel Selling Price

\begin{tabular}{llllllll}
\hline Radius & $\begin{array}{l}\text { Woody } \\
\text { Biomass } \\
\text { (tonnes/yr) }\end{array}$ & $\begin{array}{l}\text { SAF } \\
\text { Production } \\
\text { via Annex-1 } \\
\text { (MMgge/yr) }\end{array}$ & $\begin{array}{l}\text { SAF } \\
\text { Production } \\
(\mathbf{1 , 0 0 0} \\
\text { tonnes) }\end{array}$ & $\begin{array}{l}\text { Total HC } \\
\text { Production } \\
\text { (MMgge/yr) }\end{array}$ & $\begin{array}{l}\text { Total HC } \\
\text { Producti } \\
\text { on } \\
(\mathbf{1 , 0 0 0} \\
\text { tonnes) }\end{array}$ & $\begin{array}{l}\text { TCI } \\
\text { per } \\
\text { Annual } \\
\text { gge }\end{array}$ & $\begin{array}{l}\text { MFSP } \\
\text { of Total } \\
\text { HC } \\
\mathbf{( \$ / g a l )}\end{array}$ \\
\hline 50 miles & $2,542,000$ & 71 & 198 & 159 & 455 & $\$ 9.4$ & $\$ 2.44$ \\
\hline 100 miles & $4,504,000$ & 126 & 351 & 283 & 807 & $\$ 8.2$ & $\$ 2.24$ \\
\hline 200 miles & $9,610,000$ & 269 & 749 & 603 & 1,721 & $\$ 7.6$ & $\$ 2.06$ \\
\hline
\end{tabular}

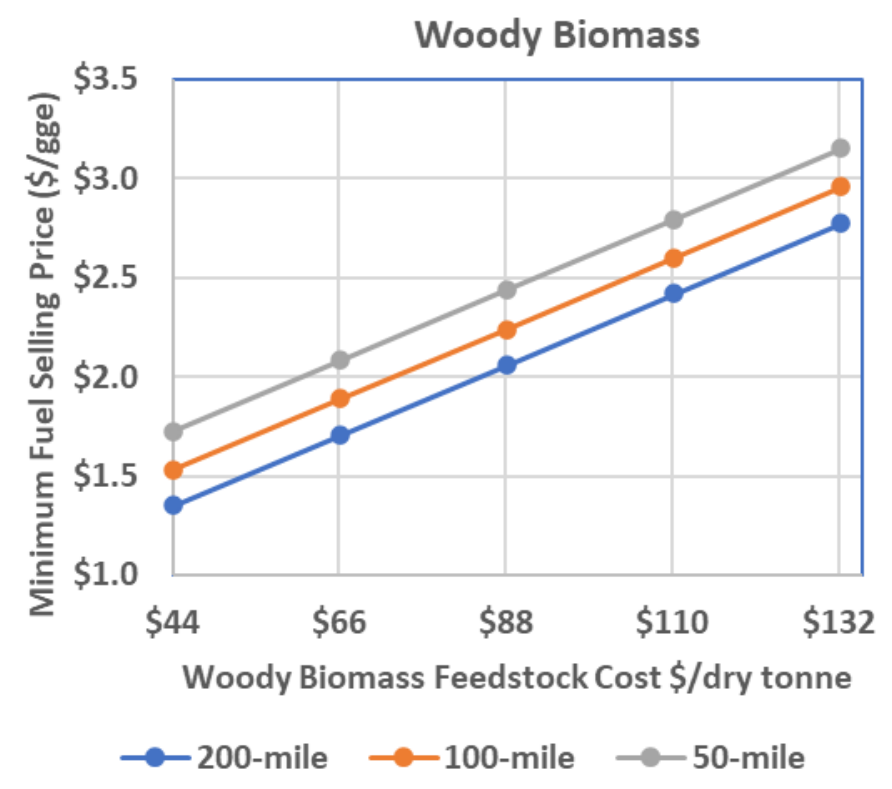

Figure 10. Cost variations from three scenarios and woody feedstock prices

\subsubsection{Crop Residue SAF Production Estimates}

The HFS-SIP pathway could produce SAF using herbaceous biomass feedstock, such as crop residues. Assuming that crop residue cost is about $\$ 66$ per dry tonne, the MFSP of the hydrocarbon from the HFS-SIP pathway is estimated at about 3-135 MMgge/yr. This feedstock and pathway are only economically viable with sourcing feedstock in a 200 -mile radius at a cost of less than $\$ 66 /$ tonne. Table 10 shows the HFS-SIP jet fuel production potential from crop residues within 50-, 100-, and 200-mile radius of a targeted location. Both the MFSP and TCI are high for this feedstock and pathway. Hydrogen demand for the HFS-SIP pathways is 115 grams 
hydrogen per gge of hydrocarbon fuel product, mainly to saturate bioderived intermediates to make hydrocarbon fuels.

Table 10. Crop Residue SAF Production and Minimum Fuel Selling Price

\begin{tabular}{lllllll}
\hline Radius & $\begin{array}{l}\text { Crop } \\
\text { Residues } \\
\text { (dry } \\
\text { tonnes/yr) }\end{array}$ & $\begin{array}{l}\text { SAF } \\
\text { Production } \\
\text { via Annex-3 } \\
\text { (MMgge/yr) }\end{array}$ & $\begin{array}{l}\text { SAF } \\
\text { Production } \\
\text { (tonnes) }\end{array}$ & $\begin{array}{l}\text { MFSP of } \\
\text { Total HC } \\
\text { (\$/gal, in } \\
\mathbf{2 0 1 7} \mathbf{)}\end{array}$ & $\begin{array}{l}\text { TCI } \\
\text { per } \\
\text { Annual } \\
\text { gge }\end{array}$ & $\begin{array}{l}\text { MFSP of Total } \\
\text { HC (\$/gal, } \\
\text { without } \\
\text { Feedstock Cost) }\end{array}$ \\
\hline 50 miles & 75,000 & 3 & 9,702 & $\$ 9.72$ & $\$ 50.0$ & $\$ 8.16$ \\
\hline 100 miles & 426,000 & 20 & 55,105 & $\$ 6.04$ & $\$ 21.8$ & $\$ 4.47$ \\
\hline 200 miles & $2,900,000$ & 135 & 376,050 & $\$ 5.39$ & $\$ 12.1$ & $\$ 3.82$ \\
\hline
\end{tabular}

\subsection{Role of Airlines and Airport Owners in SAF Production}

Many airlines have entered into off-take agreements with SAF producers, and Table 11 highlights the existing producers and airlines purchasing their fuel in the United States. ${ }^{18}$ In another less common example of airline involvement in SAF, United Airlines invested \$30 million directly in Fulcrum BioEnergy in 2015 (Fulcrum BioEnergy 2015). Anticipated future SAF producers have entered into off-take agreements with numerous airlines. The following includes some known agreements per announcements but certainly does not capture all off-take agreements between future producers and airlines: Gevo (Delta, Scandinavian Airlines), Fulcrum (Cathay Pacific, United), LanzaTech (All Nippon), Northwest Advanced Bio-Fuels (Delta), and Red Rock (FedEx, Southwest). Also, conventional jet fuel suppliers and third-party fuel marketers enter into off-take agreements with SAF producers. One example is Telluride Airport receiving Neste SAF via Avfuel — an aviation fuel supplier. Another is an agreement between Neste and Shell where the former will supply SAF and the latter will distribute it.

Table 11. SAF Off-Take Agreements

\begin{tabular}{|c|c|c|c|c|}
\hline $\begin{array}{l}\text { Fuel } \\
\text { Producer }\end{array}$ & Airline & $\begin{array}{l}\text { Start of Off-Take } \\
\text { Agreement }\end{array}$ & $\begin{array}{l}\text { Length of } \\
\text { Agreement (years) }\end{array}$ & Off-Take Volume \\
\hline \multirow[t]{3}{*}{ Neste } & Alaska Airlines & 2020 & 4 & Unknown \\
\hline & American Airlines & 2020 & 3 & $\begin{array}{l}9 \text { million gallons over } 3 \\
\text { years }\end{array}$ \\
\hline & JetBlue & 2020 & Unknown & Unknown \\
\hline \multirow{3}{*}{$\begin{array}{l}\text { World } \\
\text { Energy }\end{array}$} & KLM & 2016 & Unknown & Unknown \\
\hline & JetBlue & 2021 & 3 & 1.5 million gallons per year \\
\hline & United & 2016,2019 & Unknown & $\begin{array}{l}\text { Up to } 10 \text { million gallons } \\
\text { between } 2019 \text { and } 2021 \text {; } \\
\text { previous volumes unknown }\end{array}$ \\
\hline
\end{tabular}

Sources: Neste—Alaska Air 2020, American Airlines 2021, JetBlue 2020; World Energy-IACO 2021, S\&P Global 2021, United Airlines 2019.

\footnotetext{
${ }^{18}$ An off-take agreement is where the off-taker (airline, fuel marketer, fuel supplier) enters into an agreement with a SAF producer to purchase their fuel. Agreements typically include a start date for delivery of fuel, volume of fuel, and the length of contract.
} 
Although airports do not buy jet fuel, many are interested in SAF use as a method to meet their greenhouse gas reduction goals, support state climate targets, and benefit local airport communities. Airport owners can bring together airlines, fuel suppliers, fixed-based operators who manage airport refueling infrastructure, and related parties to identify the best methods to bring SAF blends to their airport(s). This study and those conducted by Port of Seattle (owner of Seattle-Tacoma International Airport) and San Francisco International Airport educate and prepare the local supply chain to receive, blend, and dispense SAF/Jet A blends at airports (Port of Seattle 2016; SFO 2019). Two Port of Seattle reports also investigated the potential for regional SAF production and another on funding sources and how their airport could participate in reducing costs without directly buying SAF (Port of Seattle 2020; Klauber et al. 2017).

Although SAF could be sourced from other areas of the United States or imported, an evaluation of local production was conducted due to the potential positive impacts of a circular economy by converting local waste feedstocks into SAF for use at nearby airports. SAF produced locally would incur lower fuel delivery costs to the port district compared with fuels produced farther away. Local and state governments have sponsored studies for biofuel plant resource assessments to use waste feedstocks, add value to agriculture in their region, create jobs, and additional local economic impacts. There have also been instances of state and local governments offering investment and production incentives to encourage the building of biofuel plants in a region.

\section{SAF Supply Chain Logistics}

The method of moving fuels throughout the country depends on the location of production, fuel type, and volume. The modes of transport for fuels include barge, ship, pipeline, rail, ship, and truck (Figure 11). The same rail cars and barges are used to move multiple types of fuels. Dedicated trucks are used to move Jet A from terminals or refineries to airports where pipelines are not available. ${ }^{19}$ Biofuels are typically moved by rail, truck, and barge, whereas Jet A travels primarily by pipeline. A blend of SAF and Jet A could move by pipeline. Information on modes and associated costs are available next to each of the following icons:

Barges are flat-bottomed vessels propelled by tugboats that operate on rivers, inland waterways, and at seaports. They are used to move large volumes of fuel throughout the United States. Barge tank capacity ranges from 420,000 to 4.2 million gallons, with an average capacity of 2.1 million gallons (Eiffel Trading 2021). The New York City area receives large volumes of fuel by barge. Costs to move fuel by barge are generally higher than pipeline and lower than rail and truck. Barge rates were reported for Houston, Texas, to Wood River, Illinois, and although not to the New York market, it demonstrates relative costs to move products by various modes. Barge costs ranged between 7.19 and 10.60 cents per gallon, with an average of 8.44 cents per gallon (Argus Media 2021). ${ }^{20}$

\footnotetext{
${ }^{19}$ Airports that do not have pipelines receive fuel by truck. Airports with pipelines and truck offloading equipment may receive fuel by truck during times of high demand where pipeline capacity is insufficient.

${ }^{20}$ Argus Media transportation mode average costs were for data years 2016 through 2018.
} 
Pipelines are the most common method of moving large volumes of fuel and generally are the lowest cost. Jet $\mathrm{A}$ is primarily moved by pipeline, and federal regulations need to be updated to allow unblended SAF to travel by pipeline. A blend of Jet A and SAF can travel by pipeline. Fuels are shipped through pipeline in batches based on fuel properties. Pipeline rates ranged from 4.97 to 5.49 cents per gallon between Houston and Linden, New Jersey, with an average of 5.18 cents per gallon (Argus Media 2021).

E= Rail is the most common method of moving biofuels, and rates are higher than barge or pipeline but lower than trucking. A single rail car has a capacity of 30,000 gallons. Fuels traveling on single-commodity, $\sim 110$-car-unit trains have lower rates than manifest multiple-commodity trains. Rail rates from Chicago to New York ranged between 17.19 and 28.89 cents per gallon with an average unit car rate of 23.48 cents per gallon and a manifest rate of 25.71 cents per gallon (Argus Media 2021).

Ships/Vessels are self-propelled and most often used to move large volumes of imported and exported fuels over large distances.

Trucks are used to deliver fuels from terminals to end users such as gas stations or airports who do not have pipeline access. ${ }^{21}$ It is the costliest method of moving fuels long distances. Trucks transporting jet fuel typically have a capacity of 8,000 gallons. Costs for moving fuels by truck are not published. Trucking costs for moving fuel between terminals and nearby gas stations are highly competitive and a few cents per gallon for short distances. Costs increase as distance increases, and that is reflected in the final fuel sales price. Airline fuel consortia and their fixedbase operators may contract with multiple companies to deliver fuel to an airport by truck.

${ }^{21}$ In some instances, trucks may be used to deliver fuel from a biofuel producer directly to an end user. 


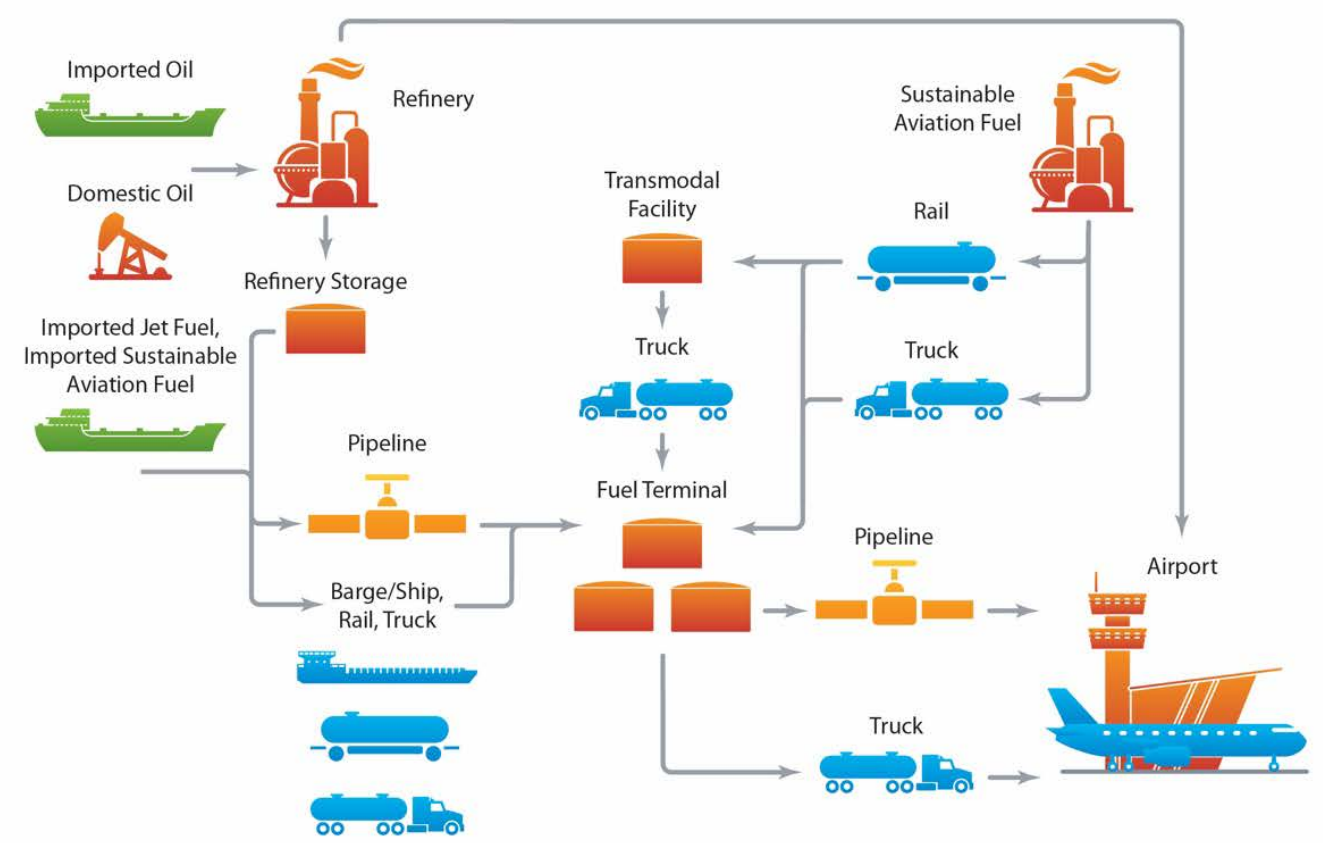

Figure 11. Fuel supply chain

If SAF is co-processed with conventional Jet A at an existing refinery, a Refinery Certificate of Quality would be generated at the refinery, and the fuel would flow through the supply chain in a business-as-usual model via pipeline directly to an airport or, more commonly, by pipeline to a terminal and then by pipeline or truck to an airport. ${ }^{22,23}$

The requirements of quality control point toward blending of SAF produced at a stand-alone facility with Jet $\mathrm{A}$ at a terminal where equipment for storage and blending are available for lease. This would result in business as usual for airports as they would receive, store, and dispense the $\mathrm{SAF} / \mathrm{Jet} \mathrm{A}$ blend to aircraft as they do today with conventional jet fuel. No investment would be needed at the airport; the infrastructure costs would occur at the terminal. SAF could be blended with Jet A at a terminal in the Linden, New Jersey, area or in the Gulf region and delivered to an area terminal via the Colonial pipeline.

There are two options for storing and blending SAF and Jet A at a terminal. With either option, fuel sampling and testing would be done to demonstrate that all ASTM standards are met, and the fuel is designated as ASTM D1655 Standard Specification for Aviation Turbine Fuels. ASTM D1655 fuels are approved for transport in pipelines and use in aircraft.

\footnotetext{
${ }^{22}$ Each batch of jet fuel produced at a refinery generates a batch number and undergoes a full conformity test to generate a Refinery Certificate of Quality.

${ }^{23}$ It is assumed that blended fuels will be delivered by pipeline for airports with pipeline access and by truck for airports without pipeline access.
} 
1. Option 1: Store SAF and Jet A in separate tanks and blend them into a third tank for injection into the pipeline for delivery to EWR, JFK, and LGA. TEB would receive the blended fuel by truck (Figure 12).

2. Option 2: Blend SAF and Jet A into the same tank and inject them into the pipeline for delivery to EWR, JFK, and LGA. TEB would receive the blended fuel by truck (Figure 12).

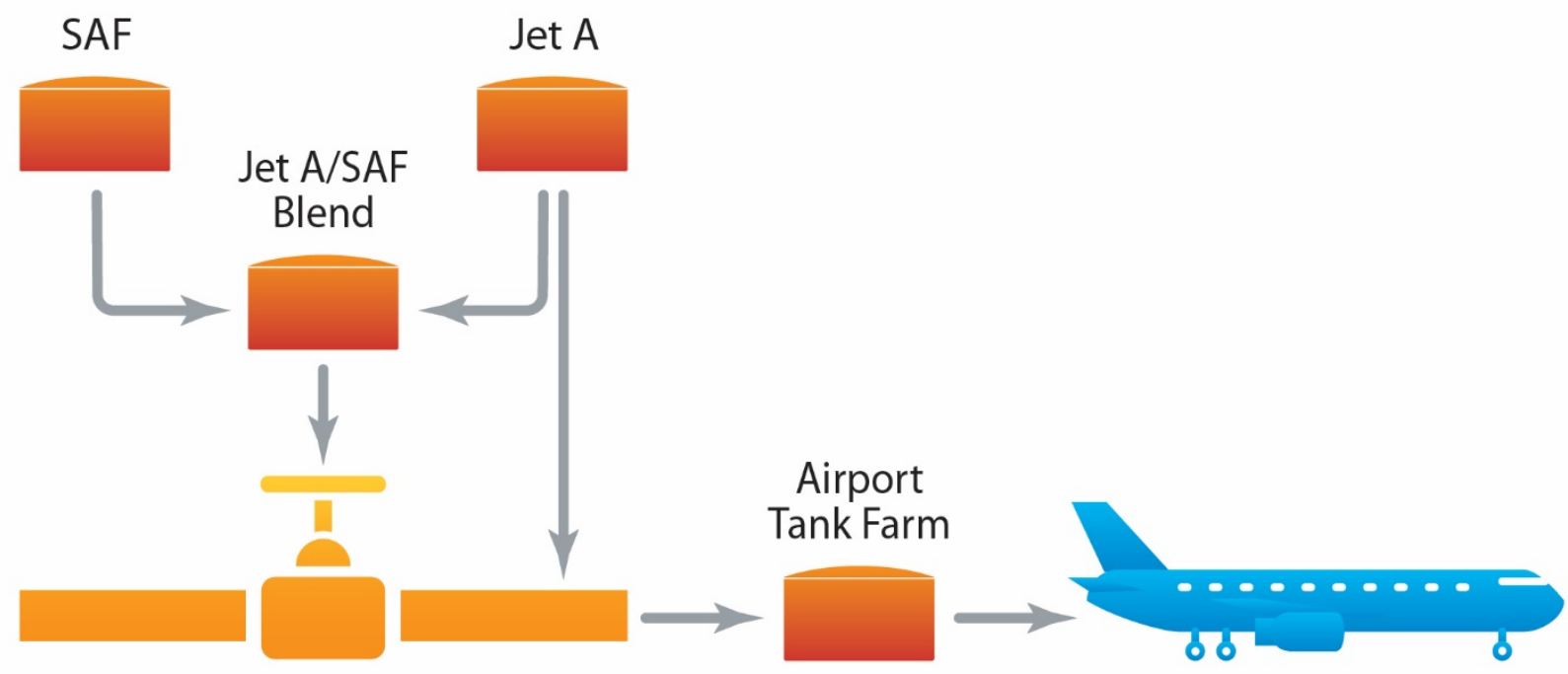

Figure 12. Option 1 for blending Jet $A$ and SAF at a terminal

Jet A/SAF

Blend

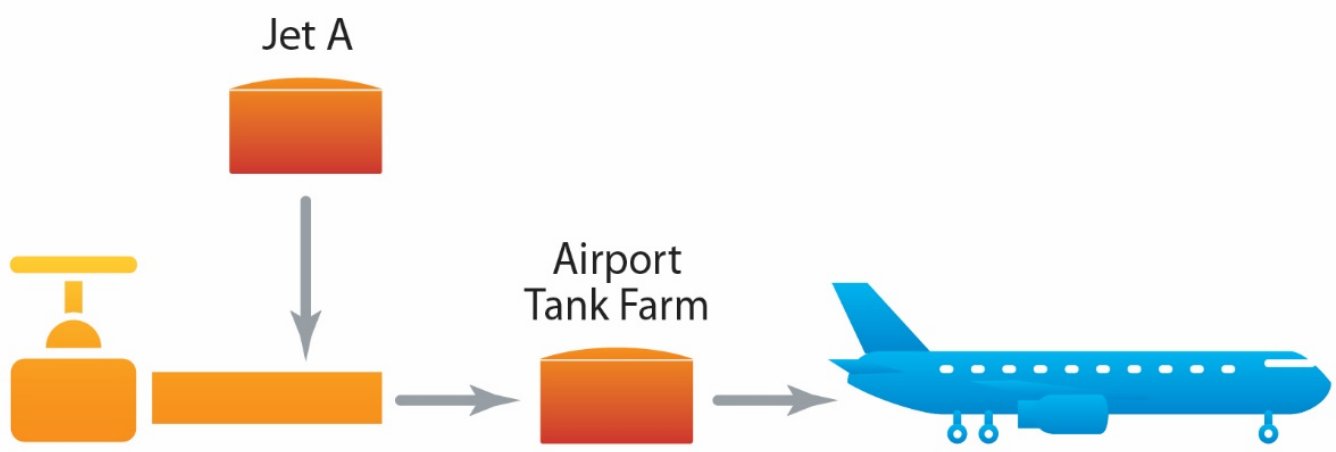

Figure 13. Option 2 for blending Jet $A$ and SAF at a terminal

The best option may vary among purchasers of jet fuel to PANYNJ airports and change as the availability of SAF increases over time. The preferences of the airlines and the terminal(s) where they lease tanks and blending equipment may dictate which option is optimal.

\subsection{Port District Terminal Options for Blending SAF and Jet A}

It is anticipated that SAF and Jet A will be blended upstream from the airport at a terminal and that there would be no investment or changes to airport infrastructure. Buckeye Partners, L.P.'s 
Linden terminal delivers fuel to EWR, JFK, and LGA. Buckeye has three pipelines serving the airports - one solely for EWR, one that serves JFK and Long Island McArthur Airport, and a combined pipeline that serves both JFK and LGA (generally, the minimum shipment on these pipelines is 10,000 barrels per batch). ${ }^{24}$ Buckeye's Linden terminal does not blend fuels and is not an option for receiving and blending SAF. There are eight terminals owned by multiple companies connected by pipeline to Buckeye's Linden facility that have the potential to blend domestic and/or imported SAF and Jet A (Figure 14). ${ }^{25}$ Figure 15 shows that the terminals are located close to one another. NREL interviewed staff from all connecting terminals to determine the ability to receive, store, and blend Jet A and SAF. There are also refineries connected to Buckeye's Linden terminal, but they are unlikely locations for blending. ${ }^{26}$ Appendix B shows the additional connections to the Linden terminal.

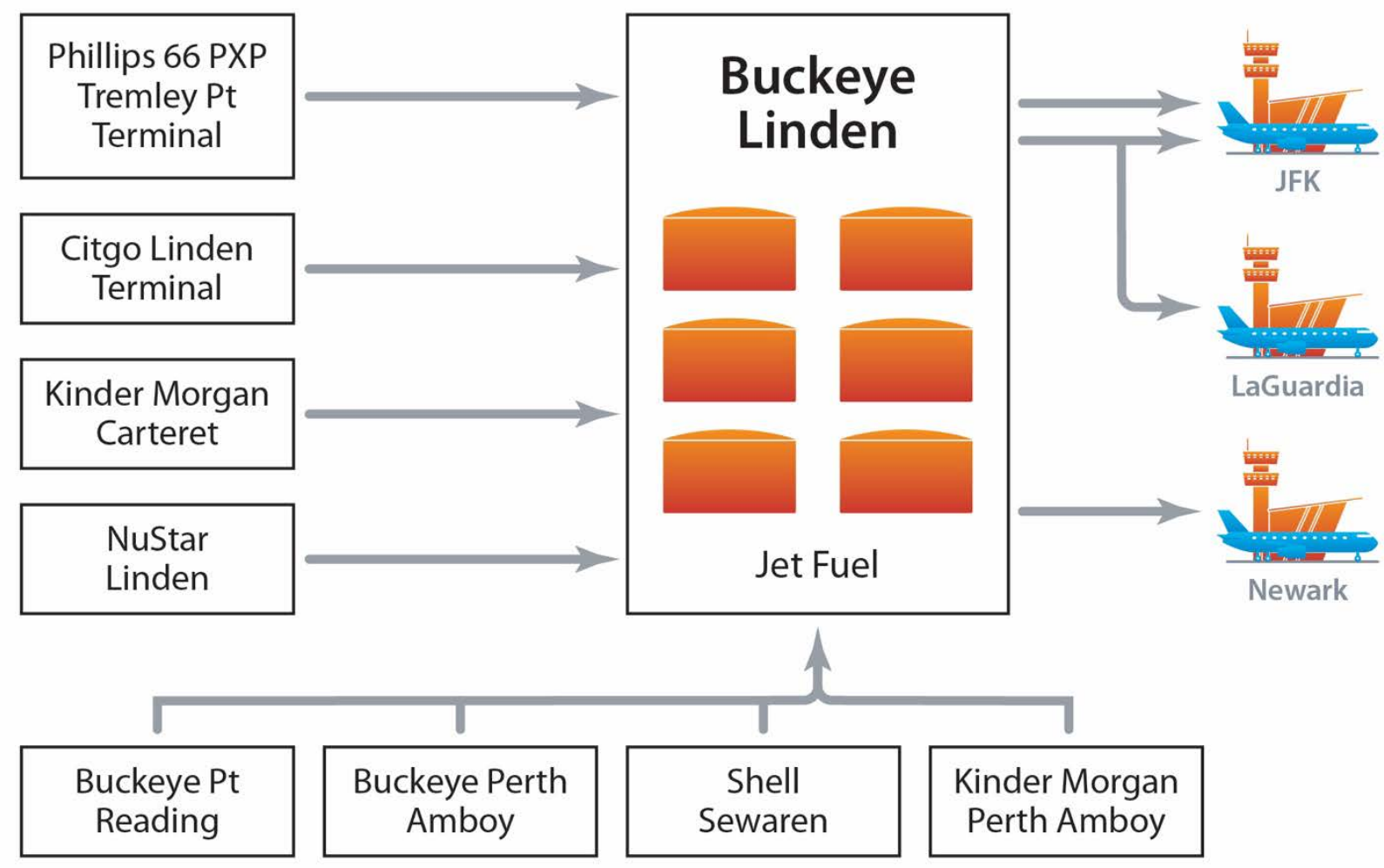

Figure 14. Terminals connected to Buckeye Linden ${ }^{27}$

Source: Buckeye Partners, L.P.

\footnotetext{
${ }^{24}$ Long Island McArthur Airport is not owned by PANYNJ and was not evaluated as part of this study.

${ }^{25}$ Figure 14 shows only fuel storage terminals connecting to Buckeye's Linden facility. There are also connections from pipelines and refineries. A full diagram of connections to this facility is available in Appendix B.

${ }^{26}$ Refineries are unlikely to accept a third-party fuel, and storage is generally sized for refinery output.

${ }^{27}$ Terminals on the left side of the graphic each have a pipeline connecting to Linden. Terminals on the bottom of the graphic connect to Linden via two shared pipelines (Appendix A).
} 


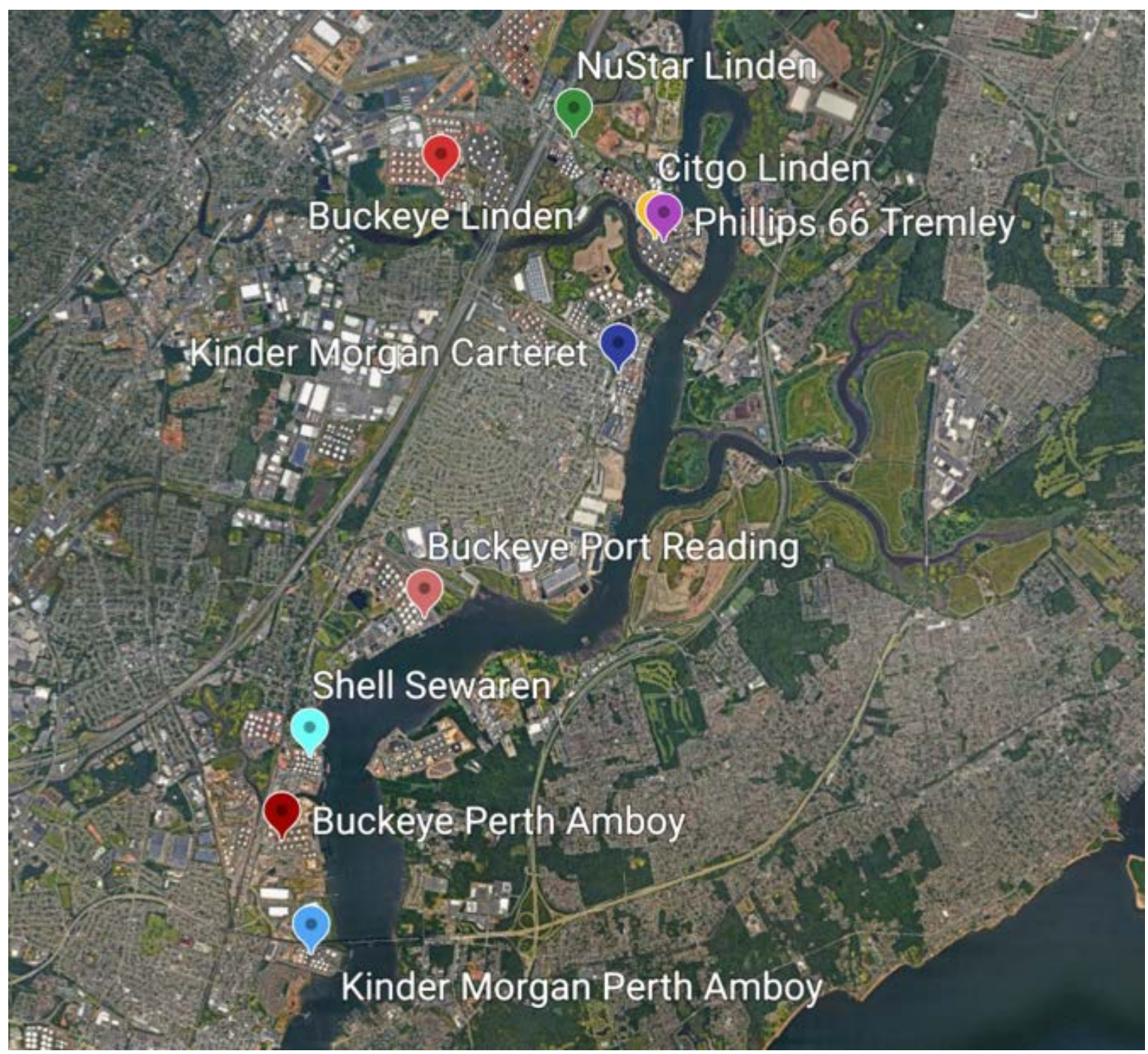

Figure 15. Terminal locations

Terminals lease fuel storage tanks and associated equipment to third parties. ${ }^{28}$ Lease terms generally run at least 1 year, and multiyear leases are common. At the time this report was prepared, all tanks were leased. Availability changes throughout a year as lease terms expire and tanks become available. It is not anticipated that storing and blending SAF and Jet A for PANYNJ would necessitate building new tanks, though most terminals have space for new infrastructure. It is expected that blending would require a capital investment for associated equipment, particularly for dedicated lines, pumps, and other ancillary equipment for offloading SAF. The purchaser of the SAF blend could opt to pay these costs upfront or incorporate them into the lease agreement that would generally run longer to allow the terminal to recoup the capital investment.

This section summarizes the infrastructure for each terminal. Fuels that a terminal handles and stores over time change based on customer needs and market demand-these summaries represent operations at these terminals as of January 2021. Some of the connected terminals store

${ }^{28}$ Terminals, including those owned by oil/refinery companies lease space as part of their business model. 
Jet A today, and some have in the past but do not at this time based on their customers' requirements. The green icons (barge, pipeline, rail, ship, and truck) indicate a terminal can receive fuels by these modes, whereas red icons indicate they cannot.

All terminals connected to the Buckeye Linden terminal stated that they would be able to receive, store, and blend SAF and Jet A. Although it is possible to use any of the terminals, some may be more advantageous as they already handle jet fuel and have the ability to receive fuels by multiple modes, particularly rail and truck, which is common for emerging biofuels. There is future potential for unblended SAF to travel by pipeline with changes in federal regulations. SAF produced at a local facility would likely be delivered to a terminal by truck. SAF produced at a stand-alone facility in another area of the United States would likely arrive by rail or truck, and by barge as volumes grow. Several terminals reported that they receive ethanol and biodiesel by barge. There is also the potential to blend SAF and Jet A in the Gulf region and transport it on the Colonial pipeline. Imported SAF could arrive directly by ship to the New York area or may go through another port, where it would be transferred to the region by rail, truck, or barge.

Table 12 lists the connecting terminals and their ability to receive fuel by barge, pipeline, rail, ship, and truck. Although a terminal may be able to receive fuel by rail or truck, it may be designated for a particular fuel or chemical, and the ability to offload SAF from these transit modes would likely require additional dedicated infrastructure to eliminate the risk of contamination.

Table 13 shows tanks and their volume ranges as well as total capacity. Some tanks are intended for fuel storage and blending, whereas other small-volume tanks are dedicated to chemicals or for loading racks, where fuels are blended in-line to fuel tanker trucks for delivery to airports, gas stations, and other end users. Not all tanks would be able to store SAF as some diesel tanks have floating roofs that do not meet storage regulations for jet fuel.

Table 12. Terminal Fuel Receipt Modes

\begin{tabular}{lccccc}
\hline \multicolumn{1}{c}{ Terminal } & \multicolumn{3}{c}{ Modes of Receipt } & \\
& Barge & Pipeline & Rail & Ship & Truck \\
\hline Buckeye Linden & $\times$ & $\checkmark$ & $\times$ & $\times$ & $\times$ \\
Buckeye Perth Amboy & $\checkmark$ & $\checkmark$ & $\checkmark$ & $\checkmark$ & $\checkmark$ \\
Buckeye Port Reading & $\checkmark$ & $\checkmark$ & $\checkmark$ & $\checkmark$ & $\checkmark$ \\
Citgo Linden & $\checkmark$ & $\checkmark$ & $\checkmark$ & $\checkmark$ & $\times$ \\
Kinder Morgan Carteret & $\checkmark$ & $\checkmark$ & $\checkmark$ & $\checkmark$ & $\times$ \\
Kinder Morgan Perth Amboy & $\checkmark$ & $\checkmark$ & $\times$ & $\checkmark$ & $\times$ \\
NuStar Linden & $\checkmark$ & $\checkmark$ & $\times$ & $\checkmark$ & $\checkmark$ \\
Phillips 66 Tremley & $\checkmark$ & $\checkmark$ & $\times$ & $\times$ & $\checkmark$ \\
Shell Sewaren & $\checkmark$ & $\checkmark$ & $\checkmark$ & $\checkmark$ & $\checkmark$ \\
\hline
\end{tabular}


Table 13. Terminal Tank and Volume Data

\begin{tabular}{lcll}
\hline Terminal & Number of Tanks & Capacity (barrels) & Volume Range (barrels) \\
\hline Buckeye Perth Amboy & 61 & $6,300,000$ & $5,000-254,000$ \\
Buckeye Port Reading & 48 & $4,400,000$ & $10,000-176,000$ \\
Citgo Linden & 43 & $3,000,000$ & $80,000-130,000$ \\
Kinder Morgan Carteret & 280 & $7,800,000$ & $2,000-260,000$ \\
Kinder Morgan Perth Amboy & 113 & $3,500,000$ & $1,190-300,000$ \\
NuStar Linden & 27 & $4,600,000$ & $5,600-320,000$ \\
Phillips 66 Tremley & 23 & $1,600,000$ & $30,000-150,000$ \\
Shell Sewaren & 75 & $4,500,000$ & $10,000-220,000$ \\
\hline
\end{tabular}

\section{Buckeye Partners, L.P.}

Buckeye Partners is a midstream fuel company with approximately 6,000 miles of pipelines and 115 fuel terminals serving the Midwest and East Coast.

\section{Buckeye Linden Terminal}
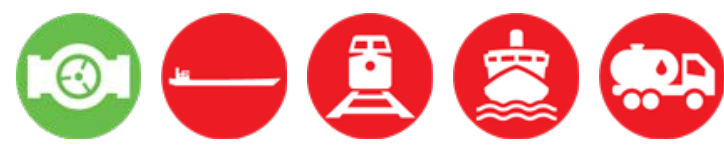

Buckeye's Linden, New Jersey, facility supplies jet fuel to EWR, JFK, and LGA via three pipelines. The Linden facility stores blendstock for oxygenate blending (the primary component in gasoline products), jet fuel, heating oil, and ultra-low-sulfur diesel. This facility recently converted several high-sulfur-diesel tanks to jet fuel in anticipation of increased demand, which has yet to develop due to COVID-19 impacts on air travel. Biofuels are not stored at Linden due to concerns of jet fuel contamination in common pipelines. Linden receives its fuel by pipeline. Truck infrastructure is used solely for offloading transmix, and there is no equipment for receiving fuel by rail, truck, or water. ${ }^{29}$ SAF and Jet A blended at a terminal upstream will be delivered to this facility for storage and delivery via pipeline to EWR, JFK, and LGA.

\section{Buckeye Perth Amboy Terminal}
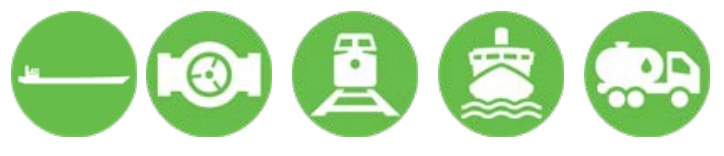

Buckeye Perth Amboy is a large terminal that can receive fuel and chemicals by all modes of transport, making this a preferred location for blending SAF and Jet A. There are 61 tanks with sizes ranging from 5,000 to 254,000 barrels, with total storage capacity of 6.3 million barrels. This facility can receive unit car trains. All ethanol and butane is received by truck. If necessary,

${ }^{29}$ Transmix is a mixture of refined products that occurs between batches of dissimilar products transported through pipelines. 
this facility has space for new tanks. There is a truck offloading rack, but it does not offload jet fuel, so infrastructure would need to be added to deliver SAF blends to TEB. Of the three Buckeye facilities, the Perth Amboy location is the optimal choice for blending SAF and Jet A due to existing infrastructure and fuels stored.

\section{Buckeye Port Reading Terminal}

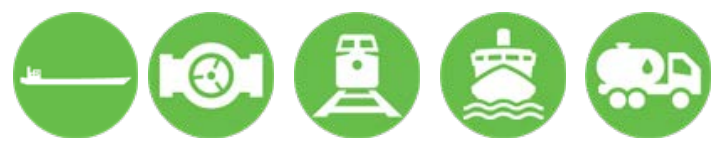

Port Reading is a large terminal with the ability to receive fuels and chemicals by all modes of transport, with an emphasis on gasoline storage. There are 48 tanks with sizes ranging from 10,000 to 176,000 barrels, with a total capacity of 4.4 million barrels. The terminal receives biofuels by both truck and barge. This facility does not handle jet fuel and has limited infrastructure to handle transmix; therefore, Buckeye's Perth Amboy is their preferred facility for blending SAF and Jet A.

\section{Citgo Linden Terminal}
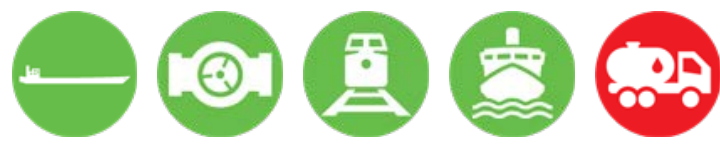

Citgo owns three refineries and 43 terminals. Citgo's Linden terminal has 43 tanks with sizes ranging from 80,000 to 130,000 barrels, with a total capacity 3 million barrels. Their Linden terminal currently stores Jet A and loads Jet A to the truck rack for delivery to airports without pipelines. There is rail on-site where Citgo receives ethanol by unit car train, but the rail infrastructure is owned by Kinder Morgan and Citgo does not have direct control of this asset. This terminal does not currently receive fuels by truck but has received biodiesel in the past. Infrastructure could be installed to receive SAF by truck but may require more investment compared with terminals currently receiving fuels by truck. If necessary, this facility has space for new tanks.

\section{Kinder Morgan}

Kinder Morgan is a midstream fuel company with approximately 9,500 miles of petroleum product pipelines and approximately 65 liquid fuel terminals.

\section{Kinder Morgan Carteret Terminal}
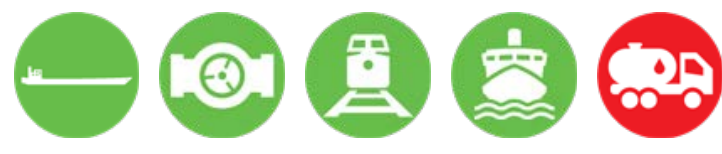

The Carteret terminal is the largest connected terminal with 280 tanks ranging in size from 2,000 to 260,000 barrels, with a total capacity of 7.8 million barrels. It has two pipeline connections to Buckeye's Linden terminal, and the current focus of operations is on the gasoline market. This terminal has stored jet fuel in the past but does not store it at the time this report was prepared. 
This terminal has a dedicated ethanol pipeline that connects to an adjacent facility. This terminal is an unlikely location for SAF blending due to the inability to receive fuels by truck and an emphasis on the gasoline market.

\section{Kinder Morgan Perth Amboy Terminal}
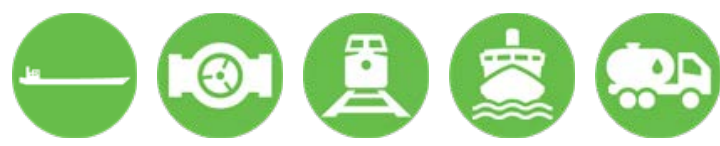

Kinder Morgan's Perth Amboy is a bulk terminal storing mostly gasoline and chemicals. There are 113 tanks ranging in size from 1,190 to 300,000 barrels, with a total capacity of 3.5 million barrels. They have the ability to receive fuel by truck, but that infrastructure is used solely for butane. They currently do not store any biofuels but have in the past. This terminal stores small volumes of Jet A. Fuels are distributed by pipeline, barge, or ship, and there is no offloading rack to trucks; therefore, this terminal cannot supply TEB.

\section{Phillips 66 Tremley Point Terminal}
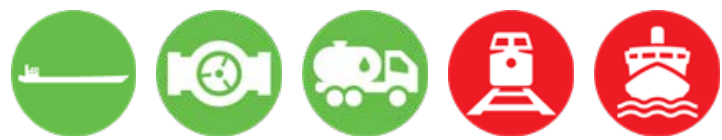

Phillips 66 has 13 refineries, nearly 6,000 miles of petroleum product pipelines, and 70 terminals. This facility has 23 tanks ranging in size from 30,000 to 150,000 barrels, with a total capacity of 1.6 million barrels. Their Tremley Point terminal stores products from their nearby Bayway refinery and leases tanks and equipment to third parties. Although rail is not on-site, it is located nearby. They receive biofuels by barge. This terminal is an unlikely location for SAF blending due to the inability to receive SAF by rail or ship.

\section{NuStar Energy L.P. Linden Terminal}
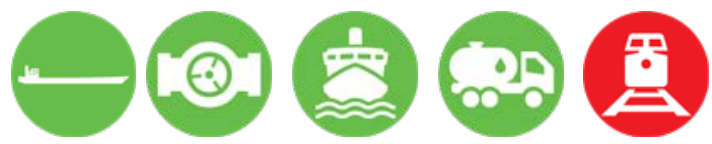

NuStar owns 5,480 miles of refined petroleum product pipelines and has 21 terminals. NuStar's Linden terminal currently stores Jet A and loads Jet A to the truck rack for delivery to airports without pipelines. NuStar owns the pipeline connecting to Buckeye's Linden terminal. Although there is not rail access on-site, there is potential for rail in the future. The facility currently receives ethanol and butane by truck. There is no additional space for new tanks, but storage is available over time as most leases run for 1-2 years. This terminal is an unlikely location for SAF blending due to the inability to receive SAF by rail.

\section{Shell Sewaren Terminal}

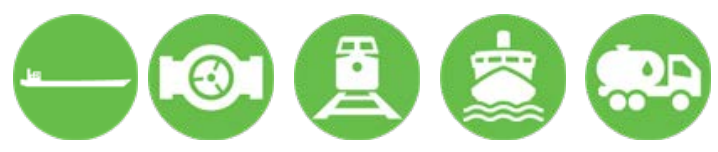


Shell has 3,800 miles of refined product pipelines and 10 terminals in the United States. Shell is involved in SAF through both investment in production technology and handling SAF logistics. This terminal can receive fuel and chemicals by all modes of transport, making this a preferred location for blending SAF and Jet A This terminal currently handles Jet A and offloads jet fuel to trucks supplying area airports. TEB receives fuel via truck from this terminal. The Sewaren terminal is able to receive ethanol, biodiesel, and other fuels by unit car train.

\subsection{PANYNJ Airport Fuel Assets and SAF Delivery to Each Airport}

PANYNJ owns the tank farms at EWR and JFK, whereas LGA's is owned by Fuel LLC, an airline consortium. Third parties (fixed-base operator) operate and maintain the tank farm on behalf of airline fuel consortia at PANYNJ airports..$^{30}$ Allied Aviation has a long history of operating and maintaining airport fueling systems and does so for EWR, JFK, and LGA. There are three tank farms at TEB, owned and operated by Atlantic Aviation, Signature, and the third jointly by Signature and Jet Aviation.

Table 14 provides infrastructure information for four PANYNJ-owned airports. EWR, JFK, and LGA receive all fuel by pipeline. TEB receives all fuel by truck. JFK has an out-of-operation barge pier, which represents a potential opportunity for another method of fuel receipt, though this would require significant capital improvements. JFK is expanding its storage capacity with two tanks under construction, and another 10 tanks are planned adding 21 million more gallons of capacity by 2039. EWR plans to expand its infrastructure by adding two tanks with total capacity of 4 million gallons and retiring 12 smaller tanks with 350,000 gallons of capacity each. A hydrant system is being installed at LGA, where aircraft are currently refueled by tanker trucks drawing supply from LGA's tank farm. ${ }^{31}$

Table 14. PANYNJ Airport Fuel System Information

\begin{tabular}{lllll}
\hline Airport & EWR & JFK & LGA & TEB \\
\hline Receipt of Fuel by Pipeline & $\checkmark$ & $\checkmark$ & $\checkmark$ & X \\
\hline Receipt of Fuel by Truck & $X$ & $X$ & $X$ & $\checkmark$ \\
\hline Receipt of Fuel by Hydrant System & $\checkmark$ & $\checkmark$ & Expected & X \\
\hline Number of Tanks & 27 & 102 & 8 & 25 \\
\hline Total Airport Storage (gal) & $13,714,000$ & $26,262,000$ & $4,750,000$ & 600,000 \\
\hline Days of Storage & 6 & 5.4 & 4 & 4 \\
\hline
\end{tabular}

Source: PANYNJ

It is expected that SAF - whether it is produced locally, in another region of the United States, or imported - would be delivered by rail, truck, barge, or ship to one of the terminals listed in Section 3.1 of this report. All SAF and Jet A blending will take place upstream of the airports at

\footnotetext{
${ }^{30}$ The purpose of airline fuel consortia, common at U.S. airports, is to pool resources and ensure quality and timely delivery of jet fuel to all airlines through shared infrastructure. The airline consortium model allows airlines to source fuel from multiple fuel producers.

${ }^{31}$ Fuel hydrant systems have pipelines underground going to each gate and aircraft are refueled from that system. Otherwise, aircraft are refueled with tanker trucks or other means.
} 
terminal(s). There is also the potential to blend SAF and Jet A in the Gulf region and deliver it to a terminal via the Colonial pipeline. The airports will receive the blended fuel by pipeline or truck as they do with conventional fuel today. The bended fuel would be batched through the pipeline and stored in the tank farm as conventional jet fuel is today. There are no anticipated changes to airport refueling procedures or infrastructure to accommodate a SAF/Jet A blend. There is no anticipated need for investment at the airport as the investment would be made upstream at the terminal(s).

\subsubsection{Newark Liberty International Airport (EWR)}

EWR receives jet fuel from Buckeye's Linden terminal on the dedicated 607L pipeline. PANYNJ owns the tank farm, and it is operated by Allied Aviation. Jet A and SAF would be blended at one of the terminals connected to Linden, or a blended SAF/Jet A would be delivered by the Colonial pipeline to one of the terminals. The SAF/Jet A blend would be delivered by pipeline to Buckeye's Linden terminal, where it would be stored and then delivered by pipeline to EWR. No changes to EWR's fuel infrastructure or procedures are expected to change to accommodate a SAF/Jet A blend.

\subsubsection{John F. Kennedy International Airport (JFK)}

JFK receives jet fuel from Buckeye's Linden terminal on the 601L and 602L pipelines. PANYNJ owns the tank farm, and it is operated by Allied Aviation. Jet A and SAF would be blended at one of the terminals connected to Linden, or a blended SAF/Jet A would be delivered by the Colonial pipeline to one of the terminals. The SAF/Jet A blend would be delivered by pipeline to Buckeye's Linden terminal, where it would be stored and then delivered by pipeline to JFK. No changes to JFK's fuel infrastructure or procedures are expected to change to accommodate a $\mathrm{SAF} / \mathrm{Jet}$ A blend.

\subsubsection{LaGuardia Airport (LGA)}

LGA receives jet fuel from Buckeye's Linden terminal on the 601L pipeline. Fuel LLC owns the tank farm, and it is operated by Allied Aviation. Jet A and SAF would be blended at one of the terminals connected to Linden, or a blended SAF/Jet A would be delivered by the Colonial pipeline to one of the terminals. The SAF/Jet A blend would be delivered by pipeline to Buckeye's Linden terminal, where it would be stored and then delivered by pipeline to LGA. No changes to LGA's fuel infrastructure or procedures are expected to change to accommodate a $\mathrm{SAF} / \mathrm{Jet}$ A blend.

\subsubsection{Teterboro Airport (TEB)}

TEB receives the majority of jet fuel by truck from Shell's Sewaren terminal. TEB's three tank farms are owned and operated by Atlantic Aviation, Signature, and Jet Aviation. It is anticipated that SAF and Jet A would be blended at the Sewaren terminal, or a SAF/Jet A blend would be delivered via the Colonial pipeline. The blended fuel would be delivered by the same trucking companies and in the same fuel trucks that deliver conventional jet fuel.

\subsection{Imported vs. Domestic Fuels}

Six of the eight terminals connected to Buckeye's Linden facility have the ability to receive imported fuel by ship. The movements of SAF will be impacted by both policy and off-take agreements between producers and end users. Imported fuel must compete on cost with 
domestically produced fuel. Initially, the demand for SAF will outpace supply, and producers are expected to sell SAF in markets willing to pay the highest price. Currently, in the United States, SAF will largely be delivered to California. If other states pass legislation that impacts fuel usage and economics, there may be a transition of SAF into those states. As SAF production expands either domestically or internationally, fuel logistics may impact decisions on where fuel is sourced.

\section{Conclusions}

SAF is an emerging fuel, and the first few domestic production facilities are expected to use various feedstocks and technology pathways. As these plants come online, technical operations and economics may favor certain feedstocks and technologies that could impact where SAF is produced. This report evaluates the potential for local production due to the potential positive impacts of a circular economy by converting local waste feedstocks into SAF for use at nearby airports. The resource assessment and techno-economic analysis found that select organic MSW and woody biomass are the most viable feedstocks for generating SAF locally. However, separating MSW and transporting any of these feedstocks are associated with additional costs not accounted for in this study. It should be emphasized that the TEA outputs carry some uncertainty related to the assumptions made for capital and raw material costs. Any new plant could have different capital and input costs that would impact the overall costs and economics that determine if a plant is viable. The TEA outputs are best used to compare different pathways and feedstocks against one another. At the most economical radius of 50 miles, there is the potential to produce 101 or 71 million gallons of SAF from select organic MSW or woody biomass, respectively. The calculated MFSP at a 50-mile radius is $\$ 2.53 /$ gallon for MSW and $\$ 2.43 /$ gallon for woody biomass. However, although MSFP for both MSW and woody biomass to SAF pathways are low, the TCI/annual gge is high at $\$ 9.4$. This indicates significant capital investment would be required for constructing the biorefinery facilities. This partially explains why there is limited investment being made today on these technologies even though they are cost competitive with economy of scales. Technology challenges and risks for large scale commercialization for individual pathways have not been explored extensively in this report.

Regardless of where SAF is produced, it needs to be bended prior to use in aircraft. NREL has identified terminals as the optimal location for blending due to existing infrastructure and the ability to designate the SAF/Jet A blend as ASTM D1655 upstream of the airports. SAF produced from a new, nearby facility would likely be delivered to a terminal by truck. SAF from distant domestic facilities would be delivered to a terminal by rail or barge, or a SAF/Jet A blend could travel from the Gulf region on the Colonial pipeline. Imported SAF would arrive by ship. With updates to federal code, it could be possible in the future to ship unblended SAF on pipelines.

EWR, JFK, and LGA receive fuel by pipeline from Buckeye's Linden terminal, which does not blend fuel. An assessment of eight upstream terminals found that they are capable of blending SAF and Jet A. However, the best near-term potential for blending is at Buckeye's Perth Amboy terminal and Shell's Sewaren terminal because both currently handle jet fuel and are able to receive fuel by all modes of transportation. SAF and Jet A could be blended at one of connected terminals and travel by pipeline to Buckeye's Linden terminal; by pipeline to EWR, JFK, and LGA; and by truck to TEB. There are no anticipated changes to infrastructure at any of the 
airports or to refueling procedures. The investment in infrastructure will take place at the terminal, and the airports will continue to receive fuel by the same pipelines (EWR, JFK, and LGA) and trucks (TEB) as they do today. 


\section{References}

Aden, A., M. Ruth, K. Ibsen, J. Jechura, K. Neeves, J. Sheehan, B. Wallace, et al. 2002.

Lignocellulosic Biomass to Ethanol Process Design and Economics Utilizing Co-Current Dilute Acid Prehydrolysis and Enzymatic Hydrolysis for Corn Stover. Golden, CO: National Renewable Energy Laboratory. NREL/TP-510-32438. http://www.nrel.gov/docs/fy02osti/32438.pdf

Alaska Airlines. 2020. "Q\&A: Why is Alaska Airlines using sustainable aviation fuel in San Francisco?.” August 13, 2020. https://blog.alaskaair.com/alaska-airlines/faq-neste-sustainableaviation-fuel/

American Airlines. 2021. "Sustainability." Accessed August 2021.

https://www.aa.com/i18n/customer-service/about-us/sustainability.jsp

Argus Media. 2021. "Argus Petroleum Transportation North America." Data range 2016-2018. https://www.argusmedia.com/en/crude-oil/argus-petroleum-transportation-north-america?page=1

Aryan, Venkat and Axel Kraft. 2021. "The crude tall oil value chain: Global availability and the influence of regional energy policies." Journal of Cleaner Production 280 (Part 1): 124616. https://doi.org/10.1016/j.jclepro.2020.124616

Avfuel. 2021. "Avfuel-Branded Telluride Regional Airport (TEX) Introduces SAF to Colorado." Accessed August 2021. https://www.avfuel.com/Details-Page/ArticleID/592/Avfuel-BrandedTelluride-Regional-Airport-TEX-Introduces-SAF-to-Colorado

Neste Corp. 2020. "Neste closes acquisition of US-based Mahoney Environmental." Biodiesel Magazine, May 4, 2020. http://www.biodieselmagazine.com/articles/2517002/neste-closesacquisition-of-us-based-mahoney-environmental

Bryan, T. 2021. "Renewable Diesel's Rising Tide.” Biodiesel Magazine, January 12, 2021. http://www.biodieselmagazine.com/articles/2517318/renewable-diesels-rising-tide

Chemical Engineering. 2021. "Chemical Engineering Plant Cost Index.” Accessed March 2021. http:/www.chemengonline.com/pci-home

DAR PRO Solutions. 2021. "Used Cooking Oil Collection Locations.” Accessed February 2021. https://www.darpro-solutions.com/locations

Davis R., L. Tao, E.C. Tan, M. Biddy, G. Beckham, C. Scarlata, et al. 2013. Process Design and Economics for the Conversion of Lignocellulosic Biomass to Hydrocarbons-Dilute-Acid and Enzymatic Deconstruction of Biomass to Sugars and Biological Conversion of Sugars to Hydrocarbons. Golden, CO: National Renewable Energy Laboratory. NREL/TP-5100-60223. http://www.nrel.gov/docs/fy14osti/60223.pdf

Davis, J. S. Haase, A. Warren. 2011. Waste-to-Energy Evaluation: U.S. Virgin Islands. Golden, CO: National Renewable Energy Laboratory. NREL/TP-7A20-52308.

https://www.nrel.gov/docs/fy11osti/52308.pdf 
Davis R., D. Fishman, E. Frank, M. Wigmosta, A. Aden, A. Coleman, P. Pienkos, et al. 2012. Renewable diesel from algal lipids: an integrated baseline for cost, emissions, and resource potential from a harmonized model. Golden, CO: National Renewable Energy Laboratory. NREL/TP-5100-55431. http://www.nrel.gov/docs/fy12osti/55431.pdf

Delta. 2019. "Delta enters offtake agreement with Gevo for 10M gallons per year of sustainable aviation fuel, creates longer term carbon solution-1." December 17, 2019. https://news.delta.com/delta-enters-offtake-agreement-gevo-10m-gallons-year-sustainableaviation-fuel-creates-long-term

Directory RNM. 2018. US Market Report.

Dutta A., M. Talmadge, J. Hensley, M. Worley, D. Dudgeon, D. Barton, P. Groenendijk, et al. 2011. Process Design and Economics for Conversion of Lignocellulosic Biomass to Ethanol: Thermochemical Pathway by Indirect Gasification and Mixed Alcohol Synthesis. Golden, CO: National Renewable Energy Laboratory. NREL/TP-5100-51400.

https://www.nrel.gov/docs/fy11osti/51400.pdf

Eiffel Trading. 2021. "What is a Tank Barge."

EREF. 2020. Analysis of MSW Landfill Tipping Fees-April 2019. The Environmental Research \& Education Foundation (EREF). March 4, 2020. https://erefdn.org/wpcontent/uploads/woocommerce uploads/2017/12/MSWLF-Tipping-Fees-2019-FINAL-revisedrevised-1-gcml72.pdf

Farm and Dairy. 2017. "Perdue soybean plant doubles Pa.'s processing capacity." September 28, 2017. https://www.farmanddairy.com/news/perdue-soybean-plant-doubles-pa-s-processingcapacity/446259.html

Freeny, L. 1976. "Spotlight. Arthur and Frank Perdue: Chicken Kings.” New York Times, September 12, 1976. https://www.nytimes.com/1976/09/12/archives/spotlight-arthur-and-frankperdue-chicken-kings.html

Fulcrum BioEnergy. 2020. "Facilities.” Accessed October 2020. https://fulcrumbioenergy.com/facilities/

.2015. “United Airlines Purchases Stake in Fulcrum BioEnergy with \$30 Million Investment.” June 30, 2015. https://fulcrum-bioenergy.com/wpcontent/uploads/2018/05/Fulcrum-Release FINAL.pdf

Humbird, D., R. Davis, L. Tao, C. Kinchin, D. Hsu, A. Aden, P. Schoen, et al. 2011. Process Design and Economics for Biochemical Conversion of Lignocellulosic Biomass to Ethanol: Dilute-Acid Pretreatment and Enzymatic Hydrolysis of Corn Stover. Golden, CO: National Renewable Energy Laboratory. NREL/TP-5100-47764. http://www.nrel.gov/docs/fy11osti/47764.pdf 
International Civil Aviation Organization (ICAO). 2021. "Offtake Agreements". Accessed March 2021. https://www.icao.int/environmental-protection/GFAAF/Pages/OfftakeAgreements.aspx

JetBlue. 2020. "Jet Blue is the First U.S. Airline to Commit to and Achieve Carbon Neutrality for All Domestic Flights.” August 13, 2020. http://mediaroom.jetblue.com/investorrelations/press-releases/2020/08-13-2020-152953291

Klauber, Adam, Annie Benn, Charlotte Hardenbol, Craig Schiller, Isaac Toussie, Misha Valk, and Jeff Waller. 2017. Innovative Funding for Sustainable Aviation Fuel at U.S. Airports: Explored at Seattle-Tacoma International. Basalt, CO: Rocky Mountain Institute. https://www.portseattle.org/sites/default/files/201803/RMI Sustainable_Aviation_Innovative Funding_SAF_2017.pdf

Liquid Environmental Solutions. 2021. "Locations.” Accessed May 2021. https://www.liquidenviro.com/locations

Mahoney Environmental. 2021. "Contact Us.” Accessed May 2021. https://www.mahoneyes.com/contact-us/

Milbrandt, Anelia, Timothy Seiple, Donna Heimiller, Richard Skaggs, and Andre Coleman. 2018. "Wet waste-to-energy resources in the United States." Resources, Conservation and Recycling 137: 32-47. https://doi.org/10.1016/j.resconrec.2018.05.023

Monfort, Jean-Christophe. 2019. "Aviation Climate Policy \& Lower Carbon Aviation Fuel." Presented at ICAO Environmental Symposium, Montreal, Canada, May 15, 2019. https://www.icao.int/Meetings/ENVSymposium/Presentations/Jean\%20Christophe\%20Monfort \%20Session $\% 208$.pdf

Moriarty, Kristi and Allison Kvien. 2021. U.S. Airport Infrastructure and Sustainable Aviation Fuel. Golden, CO: National Renewable Energy Laboratory. NREL/TP-5400-78368. https://www.nrel.gov/docs/fy21osti/78368.pdf

Pearlson M.N. 2011. "A Techno-Economic and Environmental Assessment of Hydroprocessed Renewable Distillate Fuels.” Master's thesis, Massachusetts Institute of Technology. https://dspace.mit.edu/handle/1721.1/65508

Port of Seattle. 2016. Aviation Biofuels Infrastructure Feasibility Study. Seattle, WA: Port of Seattle. P-00318568. https://www.portseattle.org/sites/default/files/201803/Aviation Biofuel Infrastructure Report Condensed.pdf

- 2020. Potential Northwest Regional Feedstock and Production of Sustainable Aviation Fuel: 2019 Report from the Port of Seattle and Washington State University. Seattle, WA: Port of Seattle. https://www.portseattle.org/sites/default/files/202008/PofSeattleWSU2019updated appendix.pdf 
Prussi, M., U. Lee, M. Wang, R. Malina, H. Valin, F. Taheripour, C. Velarde, M. Staples, L. Lonza, and J. Hileman. "CORSIA: The first internationally adopted approach to calculate lifecycle GHG emissions for aviation fuels." Renewable and Sustainable Energy Reviews 150, October 2021. https://doi.org/10.1016/j.rser.2021.111398

Red Rock Biofuels. 2020. "Lakeview Site.” Accessed October 2020. https://www.redrockbio.com/lakeview-site.html

Riazi, M. and D. Chiaramonti. 2017. Biofuels Production and Processing Technology. Boca Raton, FL: CRC Press. https://www.routledge.com/Biofuels-Production-and-ProcessingTechnology/Riazi-Chiaramonti/p/book/9781498778930

S\&P Global. 2021. "Jet Blue Airways stitches sustainability into its growth strategy.” July 27, 2021. https://www.spglobal.com/platts/en/market-insights/latest-news/agriculture/072721jetblue-airways-stitches-sustainability-into-its-growth-strategy

San Francisco International Airport (SFO). 2019. Sustainable Aviation Fuel Feasibility Study: Final Report 2019. San Francisco, CA: SFO.

https://www.flysfo.com/sites/default/files/SFO Sustainable_Aviation_Fuel Feasibility_Study_R eport.pdf

_. 2020. "A Milestone for SFO: Neste Makes First Pipeline Delivery of Sustainable Aviation Fuel.” Press Release, July 7, 2020. https://www.flysfo.com/media/pressreleases/milestone-sfo-neste-makes-first-pipeline-delivery-sustainable-aviation-fuel

SC\&A, Inc. 2020. Greenhouse Gas and Criteria Pollutant Emissions Inventory for the Port Authority of New York \& New Jersey: Calendar Year 2017. Arlington, VA: SC\&A, Inc. https://www.panynj.gov/content/dam/port-authority/about/environmental-initiatives-/EY2017Report-Final.pdf

SRI Consulting. "U.S. Producer Price Indexes - Chemicals and Allied Products/Industrial Inorganic Chemicals Index." Chemical Economics Handbook. Menlo Park, CA: SRI Consulting, October 2008.

Prussi, M., U. Lee, M. Wang, R. Malina, H. Valin, F. Taheripour, C. Velarde, M. Staples, L. Lanza, and J. Hileman. "CORSIA: The First Internationally Adopted Approach to Calculate Life-cycle GHG Emissions for Aviation Fuels.” Renewable and Sustainable Energy Reviews.

Tao, L., J. N. Markham, Z. Haq, and M. J. Biddy. 2017. "Techno-Economic Analysis for Upgrading the Biomass-Derived Ethanol-to-Jet Blendstocks." Green Chemistry 19: 1082-1101. https://doi.org/10.1039/C6GC02800D

T\&M Associates. 2015. Mercer County Improvement Authority Solid Waste and Recycling Quantification and Characterization Study. Morrestown, NJ: T\&M Associates. September 2015. http://www.mcianj.org/filestorage/133/154/T\%26M_Final_Waste_Study_-_Sept._2015.pdf 
United Airlines. 2019. "Expanding our commitment to powering more flights with biofuel." May 22, 2019. https://hub.united.com/united-biofuel-commitment-world-energy-2635867299.html

U.S. Bureau of Labor Statistics. 2021. "BLS Series Report: National employment, hours, and earnings catalog; Industry: chemicals and allied products." http://data.bls.gov/cgi-bin/srgate

U.S. Department of Energy (DOE). 2016. 2016 Billion-Ton Report: Advancing Domestic Resources for a Thriving Bioeconomy, Volume 1: Economic Availability of Feedstocks. M. H. Langholtz, B. J. Stokes, and L. M. Eaton (Leads), ORNL/TM-2016/160. Oak Ridge National Laboratory, Oak Ridge, TN. 448p. https://www.energy.gov/sites/default/files/2016/12/f34/2016_billion_ton_report 12.2.16_0.pdf

U.S. Economic Research Service (ERS). 2021. "Oil Crops Yearbook: Vegetable Oils and Animal Fats.” Accessed February 2021. https://www.ers.usda.gov/data-products/oil-crops-yearbook/

U.S. Energy Information Administration (EIA). 2020. "Jet fuel consumption, United States, Annual, (thousand barrels per day)." Accessed February 2021.

https://www.eia.gov/opendata/qb.php?category $=2135044$

U.S. Environmental Protection Agency (EPA). 2014. "Municipal Solid Waste Generation, Recycling, and Disposal in the United Sates: Facts and Figures for 2012." Washington, D.C.: EPA Solid Waste and Emergency Response. EPA-530-F-14-001. https://www.epa.gov/sites/production/files/2015-09/documents/2012_msw fs.pdf

_. 2021a. "National Overview: Facts and Figures on Materials, Wastes, and Recycling." Accessed February 2021. https://www.epa.gov/facts-and-figures-about-materials-waste-andrecycling/national-overview-facts-and-figures-materials

_ 2021b. "Public Data for the Renewable Fuel Standard." Accessed February 2021. https://www.epa.gov/fuels-registration-reporting-and-compliance-help/public-data-renewablefuel-standard

U.S. National Agricultural Statistics Service (NASS). 2020. Fats and Oils: Oilseed Crushings, Production, Consumption and Stocks: 2019 Summary. Washington, D.C.: NASS. ISSN: 24709840. https://www.nass.usda.gov/Publications/Todays_Reports/reports/cafoan20.pdf

Wang, W.-C., L. Tao, J. Markham, Y. Zhang, E. Tan, L. Batan, E. Warner, and M. Biddy. 2016. Review of Biojet Fuel Conversion Technologies. Golden, CO: National Renewable Energy Laboratory. http://www.nrel.gov/docs/fy16osti/66291.pdf 


\section{Appendix A. ASTM-Approved Production Pathways}

\section{Fischer-Tropsch Synthetic Paraffinic Kerosene (FT-SPK, ASTM D7566 Annex A1).}

Typically, biomass is converted to syngas (from biologic or petrochemical sources) using gasification, and then to jet fuel components using FT synthesis reaction. Feedstocks for this pathway are from various sources of renewable biomass such as municipal solid waste, agricultural wastes and forest wastes, wood, and energy crops. Fulcrum and Red Rock will use this technology at their respective plants under construction. The FT process was the first alternative jet fuel pathway approved for regular use (ASTM D7566 Annex A1, in September 2009) with 50\% blend limitation, producing the FT-synthesized paraffinic kerosene (FT-SPK).

\section{Hydroprocessed Esters and Fatty Acids (HEFA-SPK, ASTM D7566 Annex A2) from plant} and animal oils. HEFA fuel properties are similar to conventional petroleum fuel, but the fuel has the advantages of a higher cetane number, lower aromatic content, lower sulfur content, and potentially lower greenhouse gas emissions (Pearlson 2011). The hydroprocessing conversion technologies (e.g., hydrotreating, deoxygenation, isomerization, and hydrocracking) are at a relatively high maturity level and are commercially available. These processes are commonly used in today's refineries to produce transportation fuels. HEFA was the second process to be certificated (ASTM D7566 Annex A2, in July 2011) with 50\% blend limitation and is currently the most important process for aviation biofuel production, tested on a large scale (Riazi and Chiaramonti 2017). Since 2008, many test flights using HEFA fuel from various oil-based feedstocks (e.g., jatropha, algae, camelina, and yellow grease) have been conducted by military and commercial airlines. The use of HEFA fuels has been demonstrated in military jet flights. World Energy and Neste are producing sustainable aviation fuel (SAF) via HEFA. Recently, the so-called HEFA+ option has also entered the scene: HEFA+ would directly blend, at defined percentages, hydroprocessed vegetable oils into fossil kerosene, and not just any kerosene cut. This possibility is still under study and investigation, and is not yet ASTM-certified (Riazi and Chiaramonti 2017).

Hydroprocessed Fermented Sugars to Synthetic Isoparaffins (HFS-SIP, ASTM D7566 Annex A3) made by microbial conversion of sugars to hydrocarbons. Waste fat, oils, and greases (FOG) can be pretreated to be eligible feedstocks for this pathway. Jet fuel blended with 10\% farnesane has been ASTM-certified for flight, and several commercial flights have already flown with this blended jet fuel, including a Boeing 737. This pathway was certified in 2014 (ASTM D7566 Annex A3, in June 2014) with 10\% blend limitation.

FT-SPK with aromatics (FT-SPK/A, ASTM D7566 Annex A4). Syngas is converted to synthetic paraffinic kerosene and aromatics by FT synthesis. This process is similar to FT-SPK but with addition of aromatic components. In 2015, this pathway was approved by ASTM (ASTM D7566 Annex A4, in November 2015) with 50\% blend limitation, also considering the use of natural gas and coal as feedstock (ASTM D7566 Annex A4) (Riazi and Chiaramonti 2017).

Alcohol-to-Jet Synthetic Paraffinic Kerosene (ATJ-SPK, ASTM D7566 Annex A5). This pathway thermochemically converts cellulosic biomass-derived isobutanol to paraffinic kerosene. The thermochemical conversion includes alcohol dehydration, oligomerization, hydrogenation, and fractionation. Cost estimates for isobutanol-to-jet fuel using wood chips as 
feedstock range from $\$ 4.8$ to $\$ 6.0 /$ gge in $2011 \$$, depending on facility scale (Wang et al. 2016). Gevo and LanzaTech are among the companies developing ATJ-SPK technology, which was approved by ASTM in 2016 (ASTM D7566 Annex A5, in April 2016) with 50\% blend limitation.

Catalytic Hydrothermolysis Synthesized Kerosene (CH-SK or CHJ, ASTM D7566 Annex A6). In the CHJ process (also called hydrothermal liquefaction), clean free fatty acid oil from the processing of waste oils or energy oils is combined with preheated feed water and then passed to the catalytic hydrothermolysis reactor. There, under very high-temperature and high-pressure conditions, a single phase is formed consisting of free fatty acids and supercritical water, wherein the free fatty acids are cracked, isomerized, and cyclized into paraffin, isoparaffin, cycloparaffin, and aromatic compounds. Hydrocarbon products (6-28 carbon compounds) are n-alkanes, isoalkanes, cyclo-alkanes, and aromatics. Feedstocks for the $\mathrm{CHJ}$ process can be a variety of triglyceride-based feedstocks such as soybean oil, jatropha oil, camelina oil, carinata oil, and tung oil, and cost estimates range from $\$ 3.3$ to $\$ 4.5 /$ gge in 2011 dollars, depending on the feedstock choices (Wang et al. 2016). This SAF pathway was approved in February 2020, with $50 \%$ blend level by volume with conventional jet fuel.

Hydrocarbon-Hydroprocessed Esters and Fatty Acids (HC-HEFA-SPK, ASTM D7566 Annex A7). The HC-HEFA-SPK pathway to produce algae-based biofuel, using the hyper-growth Botryococcus braunii and led by IHI Corporation, may be blended at up to $10 \%$ by volume with conventional jet fuel. 


\section{Appendix B. Full Buckeye Linden Diagram}

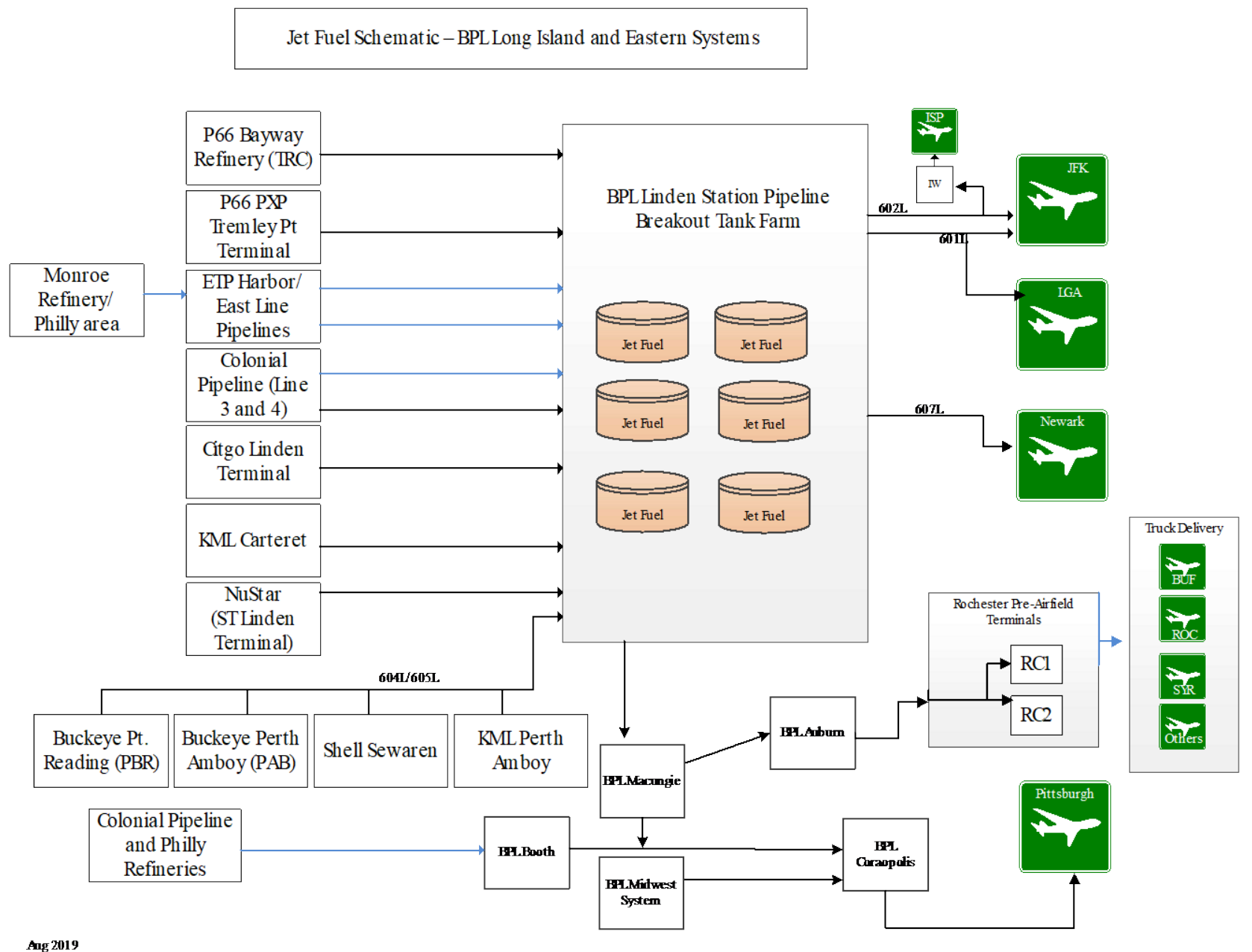

